\title{
Sensitivity of ITCZ configuration to cumulus convective parameterizations on an aqua planet
}

\author{
Yimin Liu $\cdot$ Liang Guo $\cdot$ Guoxiong Wu \\ Zaizhi Wang
}

Received: 17 July 2008/Accepted: 11 August 2009/Published online: 28 August 2009

(C) The Author(s) 2009. This article is published with open access at Springerlink.com

\begin{abstract}
This paper examines the performances of various cumulus convective parameterization schemes in the tropical atmosphere using an aqua-planet atmospheric General Circulation Model forced by zonally symmetric but latitudinally varying sea surface temperature (SST) and solar angle. The intertropical convergence zone (ITCZ) is represented by intense precipitation. The assigned Control experiment with a specific SST distribution, as designated by the Aqua Planet Experiment, yields a single ITCZ when Zhang's scheme or Manabe's scheme is employed, whereas a double ITCZ occurs when Tiedtke's scheme is used. The key to the occurrence of a double ITCZ is latitudinal variation in evaporation within the boundary layer. Such variation is induced mainly by latitudinal variation in the zonal wind speed, with the existence of a calm belt at the equator and a maximum wind speed located off the equator, arising from the evaporation-wind feedback (EWF) mechanism. The latitudinal distribution of evaporation results in a decrease in the height of the lifting condensation level in areas off the equator and an increase at the equator. The occurrence of a single ITCZ in Zhang's scheme is attributed to the use of a Convective Available
\end{abstract}

Y. Liu $(\bowtie) \cdot$ L. Guo · G. Wu

State Key Laboratory of Numerical Modeling for Atmospheric Sciences and Geophysical Fluid Dynamics,

Institute of Atmospheric Physics, Chinese Academy of Sciences, 100029 Beijing, People's Republic of China

e-mail: lym@lasg.iap.ac.cn

L. Guo

Department of Meteorology, University of Reading,

Reading, UK

Z. Wang

National Climate Center, China Meteorological Administration, 100081 Beijing, People's Republic of China
Potential Energy criterion by which convection occurs more readily at the equator. As a result, a precipitation maximum is maintained at the equator via a prevailing Conditional Instability of the Second Kind mechanism.

Keywords Double ITCZ · Parameterization of cumulus convection - Aqua planet experiment . Evaporation-wind feedback $\cdot$ CISK

\section{Introduction}

The intertropical convergence zone (ITCZ) is one of the dominant features of the tropical atmosphere, and has been examined in many previous studies. For example, Hubert et al. (1969) and Bjerknes et al. (1969) examined spatial and temporal variations in the ITCZ based on satellite observations. Although a double ITCZ has been found over the eastern Pacific during the boreal spring, Hubert et al. (1969) concluded it to be a misconception to consider such a feature to be characteristic of tropical circulation. Bjerknes et al. (1969) also found that the ITCZ was not exactly located at the equator, attributing this to the spatial distribution of sea-surface temperature (SST), with equatorial upwelling displacing the ITCZ away from the equator.

Subsequent studies have focused on the cause of the offequatorial location of the ITCZ, but have devoted relatively little attention to explaining the existence of a double ITCZ in the model tropics. Most works have concentrated on the dynamics of near-equatorial disturbances. Charney (1971) employed the hybrid dynamic-thermodynamic theory (i.e., conditional instability of the second kind, CISK) to explain the latitudinal location of the ITCZ. The CISK theory is a popular approach that explains how thunderstorms can 
evolve and become organized into hurricanes (Charney and Eliassen 1964). The theory involves a positive feedback between (1) deep moist convection associated with efficient Ekman pumping, and (2) large-scale boundary-layer circulation associated with the convergence of water vapor. Holton et al. (1971) explained the latitudinal location of the ITCZ based solely on the efficiency of Ekman pumping. Instead of using zonal symmetry, the authors emphasized that the ITCZ consists of many propagating synoptic waves. Lindzen (1974) offered an explanation based on wave-CISK, in which low-level tropical convergence is formed in response to inviscid internal wave forcing rather than Ekman pumping.

Waliser and Somerville (1994) proposed a mechanism that explains the off-equatorial location of convection. They argued that neither zonally propagating disturbances nor an off-equatorial maximum SST is required for convection to occur off the equator. Instead, they suggested that convection occurs some $4-12^{\circ}$ off the equator because low-level convergence is dynamically maximized in this region, and the convergence of moist static energy is enhanced. In contrast, Tomas and Webster (1997) emphasized the role of the cross-equatorial surface pressure gradient in determining the latitudinal location of the ITCZ.

The double ITCZ is also a topic of frequent discussion regarding simulations using general circulation models (GCMs). It is well documented that an excessively strong double ITCZ is a common problem in coupled GCMs and atmospheric GCMs (AGCMs), although more pronounced in the former than in the latter (Lin 2007). Generally, the mean state and feedback biases already exist in AGCMs, but are amplified in ocean-atmosphere coupling. Zhang (2001) reported that the double ITCZ is a significant feature of the tropical climate. In contrast to the studies mentioned above, Zhang suggested that the double ITCZ is more closely related to the surface thermal conditions than to atmospheric internal dynamics.

The double ITCZ is an unresolved issue in aqua-planet models. Hayashi and Sumi (1986) showed that a double ITCZ could form when the maximum SST is located at the equator. Numaguti and Hayashi (1991) used Kuo's (1974) cumulus convection parameterization and Manabe et al.'s (1965) moist convective adjustment scheme in an aquaplanet model. The double ITCZ formed in the experiment using Kuo's scheme, whereas a single ITCZ was observed when Manabe's scheme was used. The authors proposed that in the experiments performed using Kuo's scheme, the evaporation-wind feedback of the zonal-mean fields contributed to the separation of the single ITCZ into double bands.

Hess et al. (1993) carried out experiments similar to those of Numaguti and Hayashi (1991), and obtained similar results; however, they attributed their results to zonally propagating equatorial waves, following the theory of Holton et al. (1971). Sumi (1992) also used Kuo's (1974) cumulus convection parameterization and Manabe et al. (1965) moist convective adjustment scheme in an aquaplanet model, but found that the results were not sensitive to the choice of scheme. The author attributed the occurrence of a double ITCZ to enhanced horizontal resolution; however, Sumi's conclusions may have been limited by the fact that the SST and solar angle employed in the aqua-planet model were globally and temporally uniform. Kirtman and Schneider (2000) followed the study of Sumi (1992) by employing the relaxed Arakawa-Schubert scheme, and obtained a single ITCZ on the equator.

Recently, Chao and Chen (2004) used the aqua-planet model with uniform SST and solar angle, as employed by Sumi (1992), but with the Arakawa-Schubert and Manabe schemes. They found that the ITCZ occurs at the latitude where a balance exists between two types of attraction: one related to the Coriolis parameter, which pulls the ITCZ toward the equator, and the other related to convection, which pulls the ITCZ poleward. The occurrence of a balance between these two attractions at the equator yields a single ITCZ on the equator, whereas a balance located north and south of the equator yields a double ITCZ straddling the equator. The second attraction is more strongly dependent on the choice of cumulus convection parameterization. Chao and Chen (2004) argued that the more stringent the criterion employed for convection to occur, the more likely the ITCZ is concentrated in a restricted area on the equator.

In the present paper, we also consider how the stringent criteria employed in various cumulus convection parameterizations affect the existence of a double ITCZ in an aqua-planet model, using a latitudinally varying SST distribution that yields some new results.

The remainder of the paper is organized as follows. In Sect. 2, we introduce the employed model and experiment design. Primary results from three different cumulus convection parameterizations are also presented. In Sect. 3, we discuss different behaviors of the ITCZ arising from different thresholds employed for triggering deep convection in the cumulus convection parameterization schemes, and describe the relationship between surface evaporation and cumulus convection. Section 4 compares the influences of the evaporation-wind feedback mechanism and the CISK mechanism on the configuration of the ITCZ. Finally, a discussion and conclusions are presented in Sect. 5.

\section{Experiment design and results}

The aqua planet experiment (APE) is specified in a similar manner to the Atmospheric Model Inter-comparison 
Program (AMIP II). As proposed by Neale and Hoskins (2000a), APE was designed to test how AGCMs respond to different characteristics of SST forcing. Two types of SST distributions are included: zonally symmetric and zonally asymmetric. The nature of the zonal mean circulation of the model is addressed with a set of five symmetric SST distributions that vary only in latitude.

The SST distributions used in the current study are shown in Fig. 1. In all cases, maximum SST is set to $27^{\circ} \mathrm{C}$ at the equator. Poleward of both $60^{\circ} \mathrm{N}$ and $60^{\circ} \mathrm{S}$, the SST remains constant at $0^{\circ} \mathrm{C}$ and sea-ice is switched off. The Control SST experiment is taken as the standard experiment because it leads to a definite, but not unrealistic, ITZC regime and forms the basic SST distribution for use in the SST anomaly experiments. More details about the SST distribution can be found in Neale and Hoskins (2000a). Additional details regarding the design requirements can be found on the APE Web site (http://www.met. reading.ac.uk/ mike/APE/ape_spec.html).

Twelve GCM groups are participating in APE (Table 1). The model employed in the present study is one of the 12 models assigned to Spectral Atmospheric Model of IAP LASG (SAMIL), as developed at the Institute of Atmospheric Physics/State Key Laboratory of Numerical Modeling for Atmospheric Sciences and Geophysical Fluid Dynamics (LASG/IAP), based on the LASG/R15L9 AGCM (Wu et al. 1996). Semi-implicit time integration is used. The time step for integration in SAMIL is $15 \mathrm{~min}$. Its physical parameterizations include the updated radiation Parametric Scheme developed by Edwards and Slingo
(1996), diagnostic cloud parameterization, and the moistconvective adjustment scheme developed by Manabe et al. (1965). Two other cumulus convection parameterizations are also transplanted into SAMIL: the Arakawa-type cumulus parameterization scheme developed by Zhang and McFarlane (1995) and cumulus convection parameterization developed by Tiedtke (1989).

In the Tiedtke scheme (1989), the occurrence of deep convection or penetrative convection is based on a moisture convergence hypothesis. It is postulated that cumulus clouds can occur when there exists a deep layer of conditional instability and large-scale moisture convergence; the mass flux at the cloud base is linked to underlying moisture convergence. An increase in vertical mass flux within the lower half of the troposphere is linked to moisture convergence into the atmospheric column. According to this hypothesis, deep convection occurs when (1) an undiluted air parcel rising adiabatically along the dry adiabatic lapse rate maintains its positive buoyancy until reaching the lifting condensation level (LCL), at which a parcel of moist air lifted dry-adiabatically would become saturated; and (2) when the large-scale moisture convergence is stronger than the moisture removed due to turbulent eddies. In the Zhang and McFarlane (1995) scheme, deep convection occurs when the integrated maximum Convective Available Potential Energy (CAPE) exceeds $70 \mathrm{~J} \mathrm{~kg}^{-1}$.

Figure 2 shows the general behavior of simulated precipitation according to the 12 models that make up the APE project. Each experiment involves a 3.5-year perpetual March integration, and the time-mean patterns of the last
Fig. 1 Sea surface temperature (SST) used in different aqua planet experiments (APE), as described by Neale and Hoskins (2000a). Unit is ${ }^{\circ} \mathrm{C}$

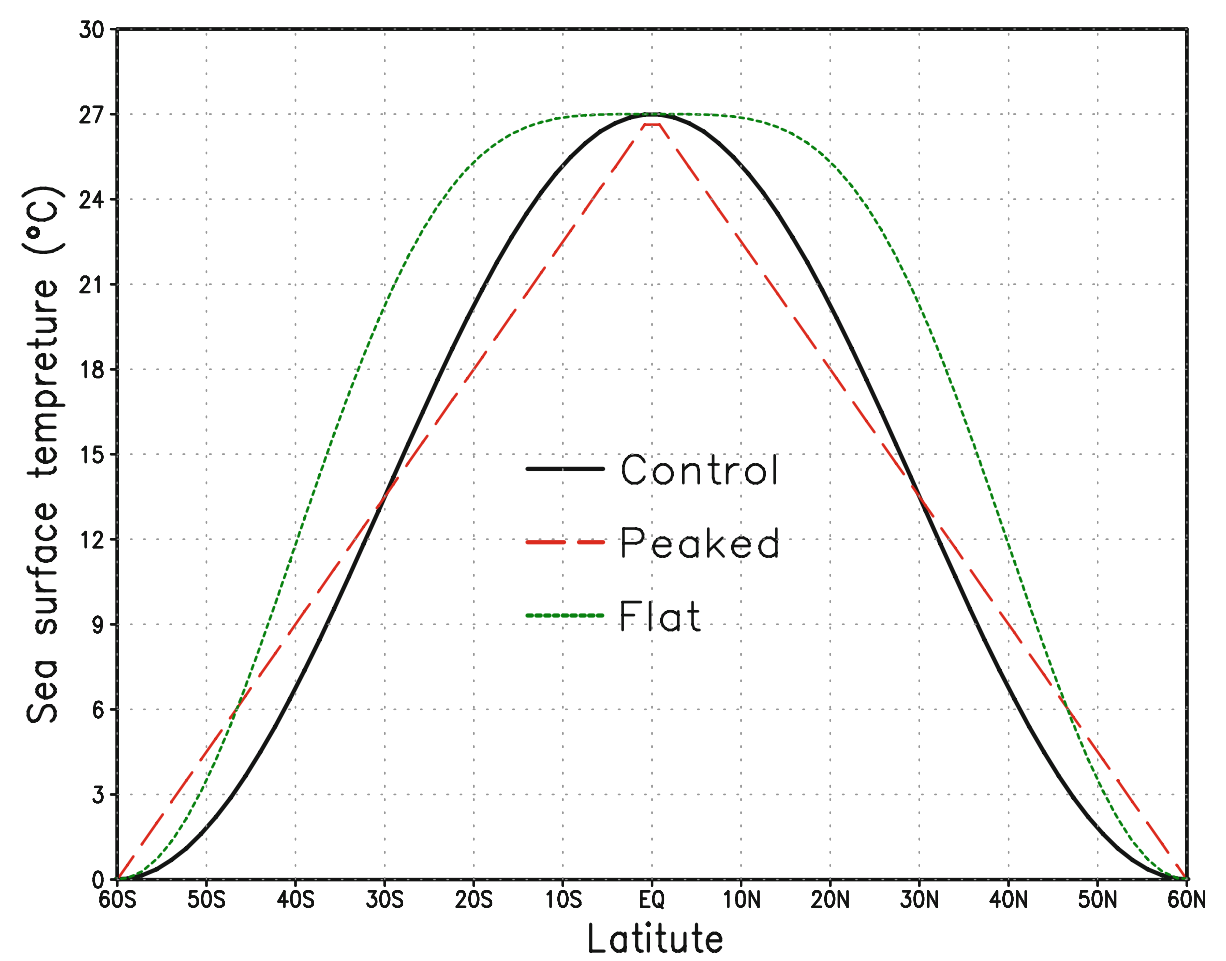


Table 1 Details of the 12 general circulation models (GCMs) participating in the aqua planet experiment (APE)

\begin{tabular}{lllll}
\hline Group & Location & Model & Resolution & Features \\
\hline AGU for APE & Japan (consortium) & AFES v.1.15 & T39 L48 & Spectral, eulerian \\
CGAM & Reading, UK & HadAM3 & N48 L30 & $3.75^{\circ} \times 2.5^{\circ}$ grid \\
CSIRO & Aspendale, Australia & CCAM-4-12 & C48 L18 & $\sim 220$ km conformal cubic grid \\
DWD & Mainz, Germany & GME 29.1.1 & ni 64 L31 & $\sim 1^{\circ}$ icosahedral-hexagonal grid \\
ECMWF & Reading, UK & IFS Cycle 29r2 & T 159 L60 & Spectral, semi-lagrangian \\
GFDL & Princeton, USA & AM2p14 & N72 L24 & $2.5^{\circ} \times 2^{\circ}$ grid \\
GSFC & Maryland, USA & NSIPP-1 & N48 L34 & $3.75^{\circ} \times 3^{\circ}$ grid \\
K1-Japan & Japan (collaboration) & CCSR/NIES 5.7 & T42 L20 & Semi-lagrangian moisture and cloud \\
LASG & Beijing, China & SAMIL & R42 L9 & Spectral, eulerian \\
MIT & Cambridge, USA & MIT-gcm & C32 L40 & $\sim 280$ km cubed sphere \\
MRI & Tokyo, Japan & MRI/JMA98 & T42 L30 & Spectral, eulerian \\
NCAR & Boulder, USA & CCSM-CAM3 & T42 L26 & Spectral, eulerian \\
\hline
\end{tabular}

3 years are used to present the climatology. Figure 2 shows the distributions of zonal-mean and time-mean precipitation of the Control, Flat, and Peak experiments for the 12 participants. In addition to performing an experiment using Manabe's scheme in SAMIL, two additional SAMIL Control experiments are carried out using the Tiedtke and Zhang-McFarlane cumulus convection parameterizations. These three experiments are referred to as $M_{\text {ori }}, T_{\text {ori }}$, and $Z_{\text {ori }}$, respectively. Thus, there are 14 integrations for the Control experiments and 12 integrations for the Flat and Peak experiments.

We use precipitation to represent the ITCZ. The width and pattern of the convective maximum depend mainly on near-equator distributions of SST. When the SST gradients become weakened in the Flat SST experiment, the single ITCZ generated in the Peak SST experiment (Fig. 2c) splits into two ITCZs (one each side of the equator), resulting in double ITCZs in all experiments (Fig. 2b), consistent with the findings of Neale and Hoskins (2000b). However, a complicated ITCZ pattern is obtained in the Control experiments (Fig. 2a). In all integrations, the precipitation patterns are similar in subtropical regions and at middle and high latitudes. Minimum rainfall appears at $20^{\circ} \mathrm{N}$ and $20^{\circ} \mathrm{S}$, with a secondary rainfall peak at $35^{\circ} \mathrm{N}$ and $35^{\circ} \mathrm{S}$. The precipitation intensities are also similar at these latitudes; however, apparent differences in precipitation occur near the equator. A single ITCZ is located at the equator in the $Z_{\text {ori }}$ experiment and in nine APE experiments (including $M_{\text {ori }}$ ); however, double ITCZs are observed in $T_{\text {ori }}$ and the remaining three APE experiments. The appearance of the double ITCZs is clearly not solely related to the SST gradient: it is also related to the choice of cumulus convection parameterization. In the following section, we will analyze the $Z_{\text {ori }}$ and $T_{\text {ori }}$ experiments (as representative examples) in detail with the aim of understanding the formation of ITCZ configuration.

\section{Behavior of the ITCZ}

Arakawa (2004) divided the main cumulus convection parameterizations into three types based on the prototype from which they were developed. The three prototypes are the moist-convective adjustment scheme of Manabe et al. (1965), the scheme proposed by Kuo (1974), and the scheme outlined by Arakawa and Schubert (1974). Both Zhang's scheme and Tiedtke's scheme are based on the work of Arakawa and Schubert, although employing a mass flux approach. Song (2005) compared the performances of Zhang's scheme and Tiedtke's scheme in the Community Atmosphere Model 2 (CAM2) developed at the National Center for Atmospheric Research (NCAR), and found that the simulated climatology obtained using the two schemes is similar to that in the AMIP experiments. Nevertheless, it remains to be explained why the Zhang and Tiedtke schemes produce different ITCZ configurations in the Control APE.

In APEs, the initial fields are constructed from the model climatology at March 15, and are interpolated to the non-topographical model levels to produce the model variables. Here, we explore the evolution of model behavior from the beginning of each experiment when the Zhang and Tiedtke schemes are used in different integrations. Figure $3 \mathrm{a}$ and $\mathrm{b}$ shows the temporal evolutions of zonal mean precipitation in the $Z_{\text {ori }}$ and $T_{\text {ori }}$ experiments, respectively, from Days 1 to 43. During the first month of integration, both experiments show double ITCZs from the first step; however, from Day 38 the double ITCZ in the $Z_{\text {ori }}$ experiment merge into a single ITCZ (Fig. 3a), 
Fig. 2 Temporal and zonal mean distributions of precipitation produced from a Control experiments based on the 11 models that make up the APE Project and 3 SAMIL integrations using different cumulus parameterization schemes; $b$ the Flat experiments; and $\mathbf{c}$ the Peaked experiments based on the 12 models shown in Table 1. Unit is $\mathrm{mm} \mathrm{day}^{-1}$ (a)
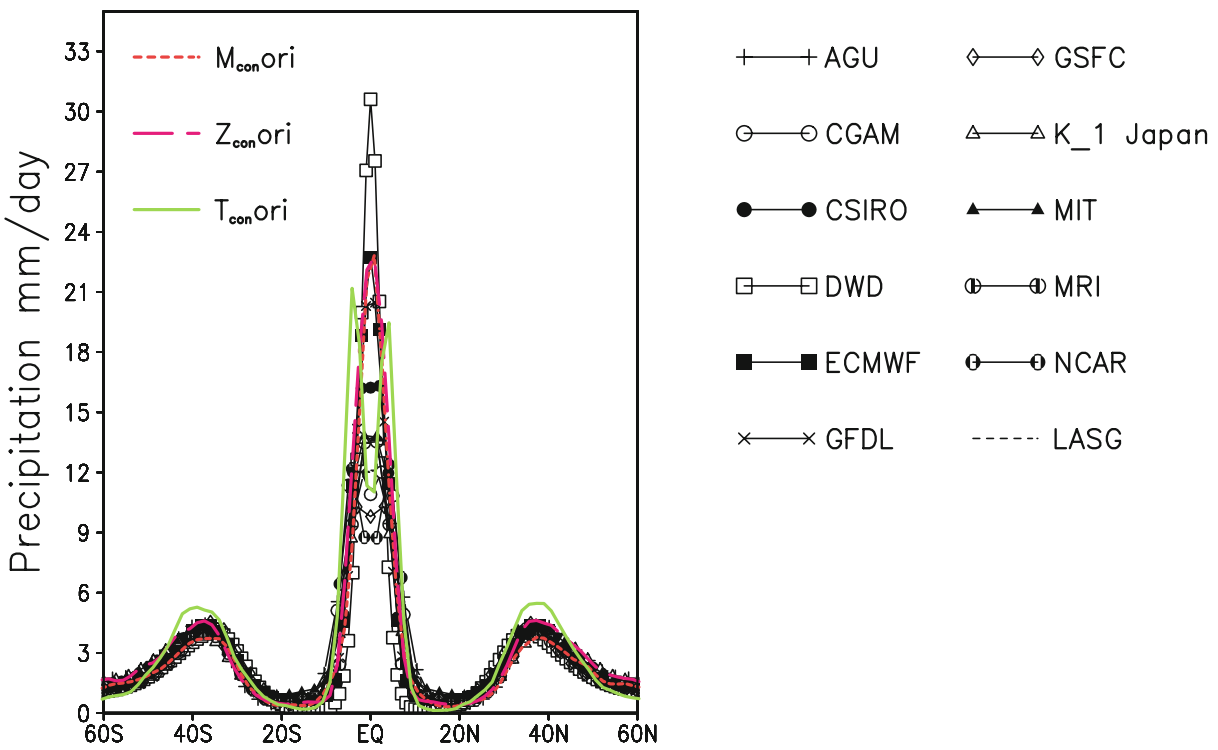

$x \times$ GFDL $\quad \cdots$ LASG (b)

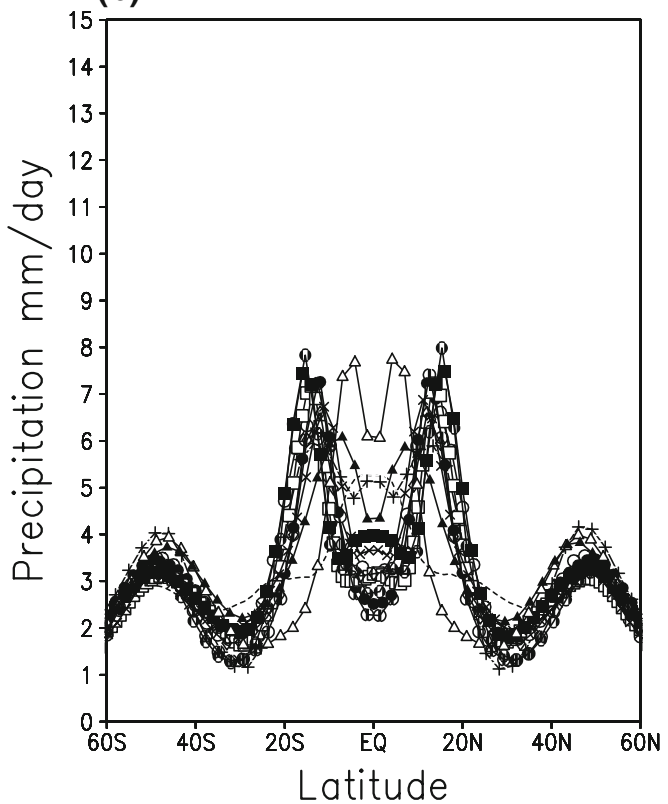

(c)

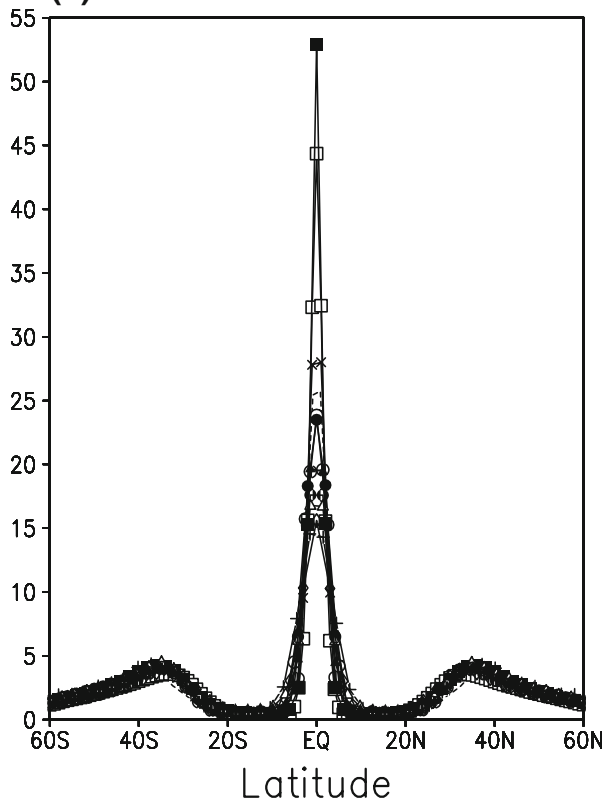

whereas the double ITCZ persists in the $T_{\text {ori }}$ experiment (Fig. 3b).

We now consider why the double ITCZs exist during the first 35 days in both experiments. Figure $4 \mathrm{a}$ shows the distribution of the initial condition of specific humidity in the $T_{\text {ori }}$ and $Z_{\text {ori }}$ experiments. At the bottom level of the model, there exist double peaks in specific humidity located at $5^{\circ} \mathrm{N}$ and $5^{\circ} \mathrm{S}$. Correspondingly, the convergence of vapor flux (Fig. 4c) shows two maxima at these latitudes. At the bottom level of the model, more water vapor exists at $5^{\circ} \mathrm{N}$ and $5^{\circ} \mathrm{S}$ than at the equator; consequently, the LCL is expected to be lower at $5^{\circ} \mathrm{N}$ and $5^{\circ} \mathrm{S}$ than at the equator. In turn, this means that convective activity occurs more readily at $5^{\circ} \mathrm{N}$ and $5^{\circ} \mathrm{S}$, thereby explaining, to some extent, why the double ITCZs exist during the first month of the $Z_{\text {ori }}$ and $T_{\text {ori }}$ runs.

The most striking feature of the $Z_{\text {ori }}$ integration is that it shifts from a double- to single-ITCZ pattern after Day 38, at which time the pattern approaches a quasi-steady state. Because Zhang's scheme requires CAPE $>70 \mathrm{~J} \mathrm{~kg}^{-1}$ for convection to develop, such a shift in ITCZ pattern indicates that the $Z_{\text {ori }}$ run must involve strong CAPE over the equator, thereby favoring the development of deep cumulous cloud and convective precipitation. This is indeed the case (see Fig. 7a), and will be discussed further below.

Comparing the threshold for triggering convection between the Tiedtke and Zhang schemes, we find that the development of deep convection in Tiedtke's scheme is 
Fig. 3 Zonal mean precipitation from Day 1 to Day 43 in the following experiments: a $Z_{\text {ori }}, \mathbf{b} T_{\text {ori }}, \mathbf{c} Z_{\text {chg }}$, and $\mathbf{d} T_{\text {chg }}$. Unit is mm day ${ }^{-1}$ (a) $Z_{\text {ori }}$

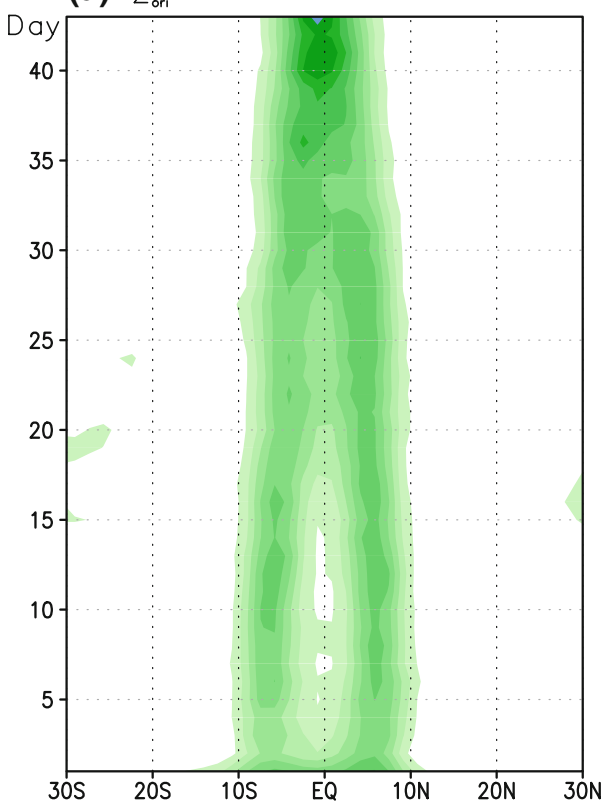

(c) $Z_{\text {chg }}$

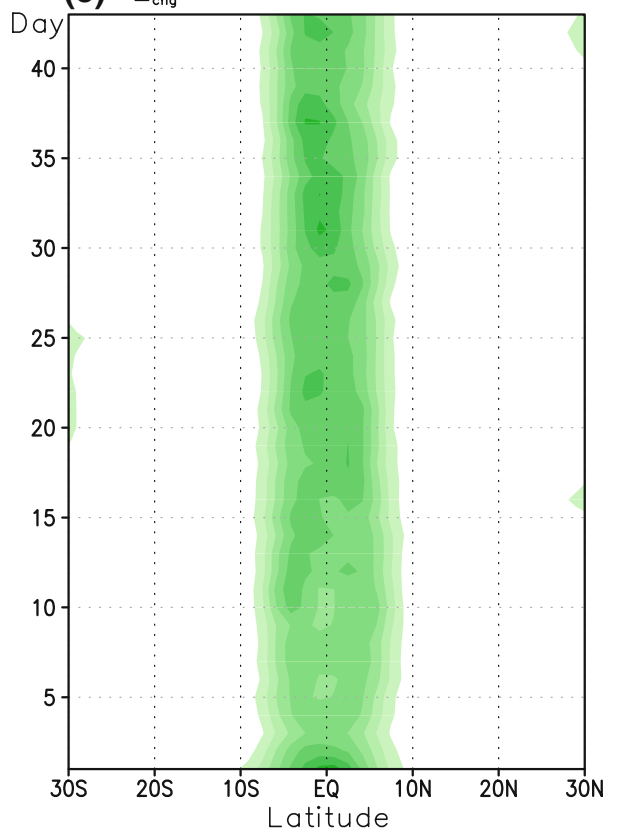

(b) $\mathrm{T}_{\text {ori }}$

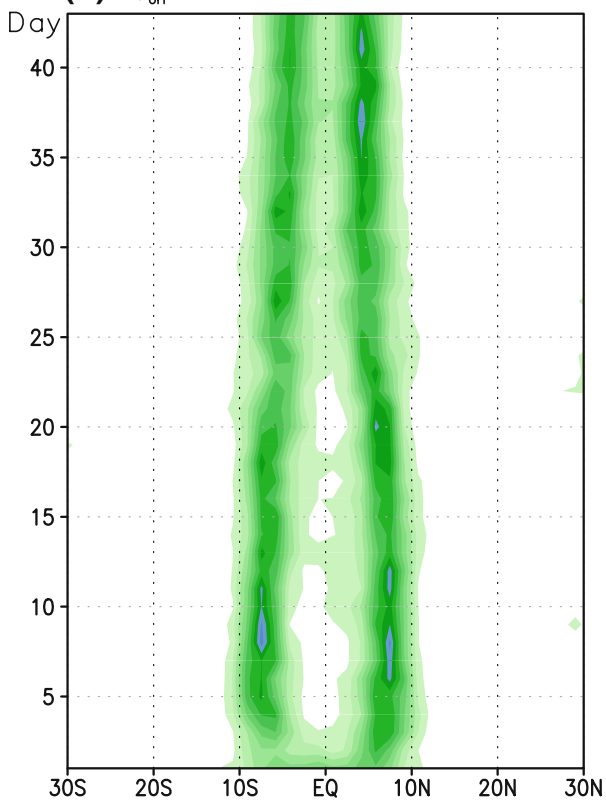

(d) $T_{\text {chg }}$

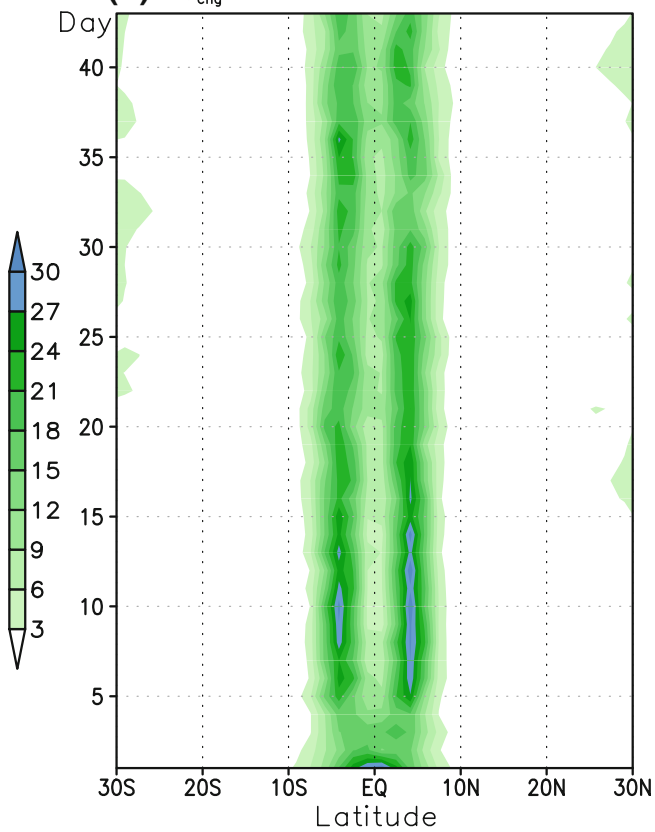

more difficult than that in Zhang's scheme if the surface air is drier and the LCL becomes higher. This occurs because only Tiedtke's scheme considers the suppression effect due to negative buoyancy during the period before the rising air parcel reaches the LCL.

It is possible that the persistent double ITCZs exist in the $T_{\text {ori }}$ run because of the existence of double moisture peaks at the initial state. To assess this initial-valuedependent hypothesis, we changed the initial condition from double peaks in specific humidity off the equator to a single maximum at the equator, then carried out similar experiments and observed the evolution of the ITCZ. Figure $4 \mathrm{~b}$ shows the revised initial specific humidity $q$ (changed from double peaks off the equator to a single strong peak at the equator), and Fig. $4 \mathrm{~d}$ shows the changed divergence of vapor flux. The corresponding sensitivity experiments (using these changed initial conditions) are referred to as the $T_{\text {chg }}$ and $Z_{\text {chg }}$ experiments, respectively.

Figure $3 \mathrm{c}$ and $\mathrm{d}$ shows the evolutions of zonal mean precipitation in the $Z_{\text {chg }}$ and $T_{\text {chg }}$ experiments, respectively, from Days 1 to 43. Because the double peaks in initial $q$ have been eliminated, a single peak in zonal mean 
(a) $\mathrm{q}$

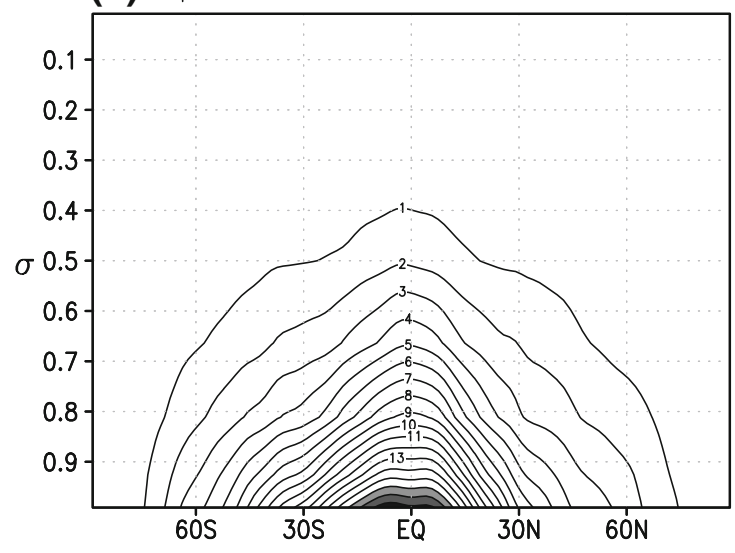

(c) $\nabla \cdot(\mathrm{Vq} / \mathrm{g})$

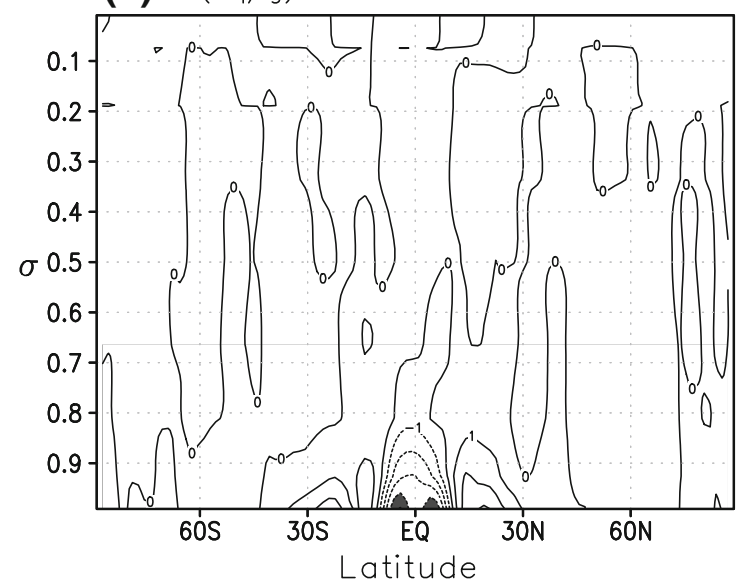

(b) $\mathrm{q}$

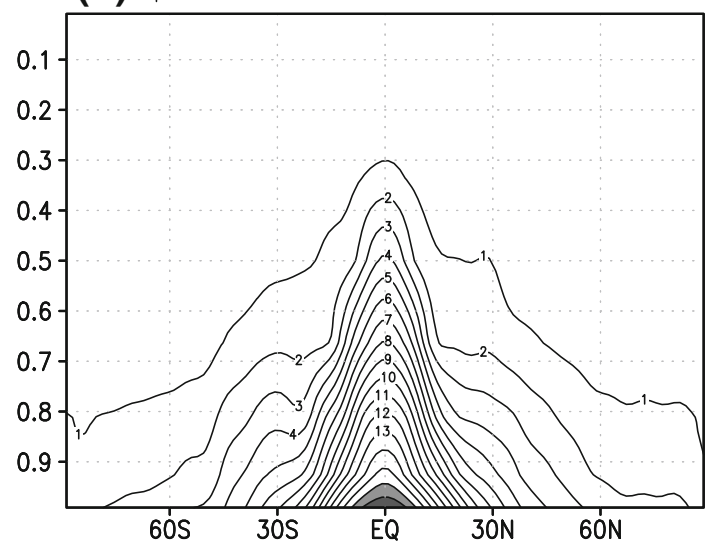

(d) $\nabla \cdot(v q / g)$

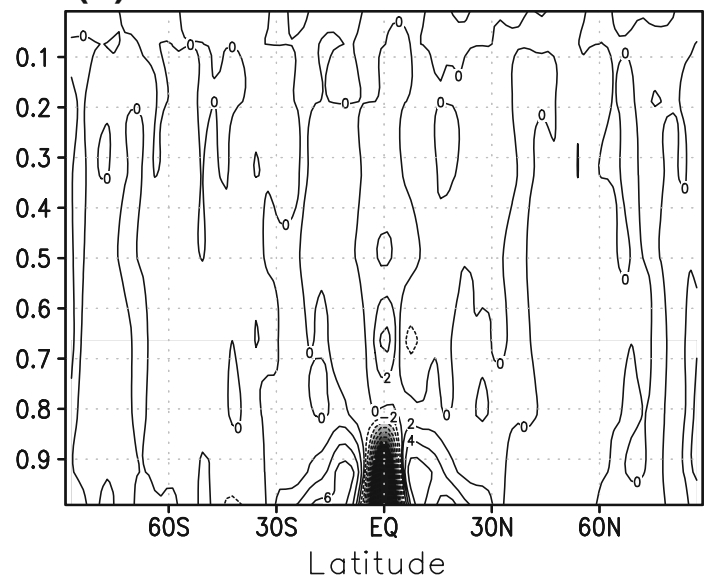

Fig. 4 Initial conditions of specific humidity $(q)$ for the $Z_{\text {ori }}$ and $T_{\text {ori }}$ experiments $\mathbf{a}$ and the $Z_{\text {chg }}$ and $T_{\text {chg }}$ experiments $\mathbf{b}$, and divergence of vapor

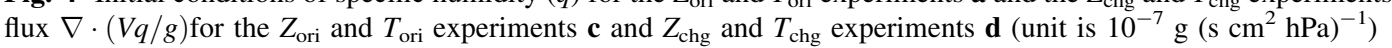

precipitation appears from the first time-step; however, in both experiments, after several days the peak splits into two branches until Day 30. A remarkable difference between the two experiments appears after about 1 month: in the $Z_{\text {chg }}$ experiment the double ITCZ merges into a single ITCZ at the equator (Fig. 3c), whereas in the $T_{\text {chg }}$ experiment the distinct double ITCZ pattern remains (Fig. 3d).

The results of the two sets of experiments described above demonstrate that initial $T$ and $q$ are not crucial elements in controlling the occurrence of a double ITCZ in Tiedtke's scheme and a single ITCZ in Zhang's scheme. There must exist a dominant mechanism in the Tiedtke scheme experiment by which the double ITCZ forms off the equator and a different dominant mechanism in the Zhang scheme experiment by which a single ITCZ forms at the equator. These mechanisms are investigated in the following section.

\subsection{Evolution of CAPE}

Song (2005) introduced Tiedtke's scheme into NCAR CAM2, and compared the performances of the two most commonly used schemes of mass-flux type (i.e., the Zhang and Tiedtke schemes). The author found that momentum transportation, midlevel convection, shallow convection, and cumulus downdrafts are not the dominant factors that determine the contrasting performances of the two schemes. Instead, a set of sensitivity experiments revealed that the major factors are the threshold for triggering convection, determination of the cloud-top height, and the treatment of updrafts.

Because the threshold for triggering convection determines whether convection occurs, it is the most important factor in terms of influencing the behavior of a convective parameterization scheme. Below, we describe the results of APE experiments performed with a focus on the impacts on 

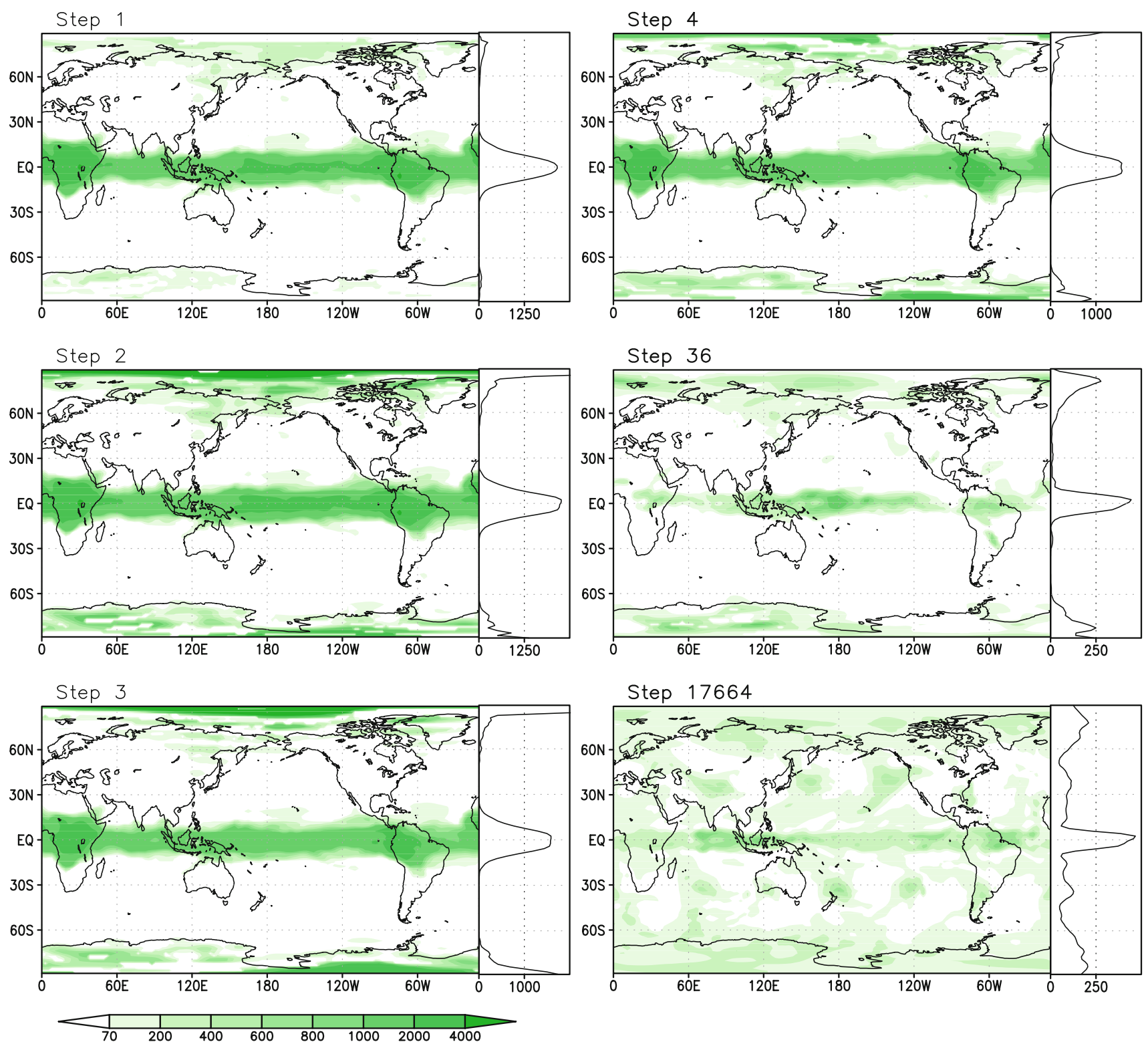

Fig. 5 Convective available potential energy (CAPE) of deep convection and its zonal mean (right-hand panels) at the integration time-steps 1, $2,3,4,36$, and 17664 in the experiment $Z_{\text {chg }}$. Unit is $\mathrm{J} \mathrm{kg}^{-1}$

the ITCZ of different thresholds for triggering convection in the Zhang and Tiedtke schemes.

Figures 5 and 6 show the distribution of CAPE for deep convection and its zonal mean at Time Steps 1, 2, 3, 4, 36, and 17664 (Day 184) of the integration in the $Z_{\mathrm{chg}}$ and $T_{\mathrm{chg}}$ experiments, respectively. In the $T_{\text {chg }}$ experiment, CAPE is largely confined to the equator at Step 1, but rapidly expands to both sides of the equator at Step 2 (Fig. 6). This occurs because at Step 1 the $q$ field shows little change compared with the initial distribution (Fig. 4b). Because $q$ decreases rapidly in areas off the equator, the LCL in these regions increases in height and does not satisfy the Tiedtke criteria for the development of convection, resulting in a lack of precipitation. In the Tiedtke scheme, CAPE is calculated only where precipitation occurs; thus, at Step 1 CAPE is confined to the equator. Soon after, once evaporation-wind positive feedback begins in the Tiedtke scheme (as discussed below), convective rainfall occurs off the equator, and the CAPE band shows a marked expansion at Step 2.

A comparison of Figs. 5 and 6 reveals a number of similarities during the first four steps. For example, both the $Z_{\text {chg }}$ and $T_{\text {chg }}$ experiments show intense CAPE in the tropics, with maximum CAPE at the equator. This finding indicates that both experiments make a strong convective adjustment to the initial condition; however, the 

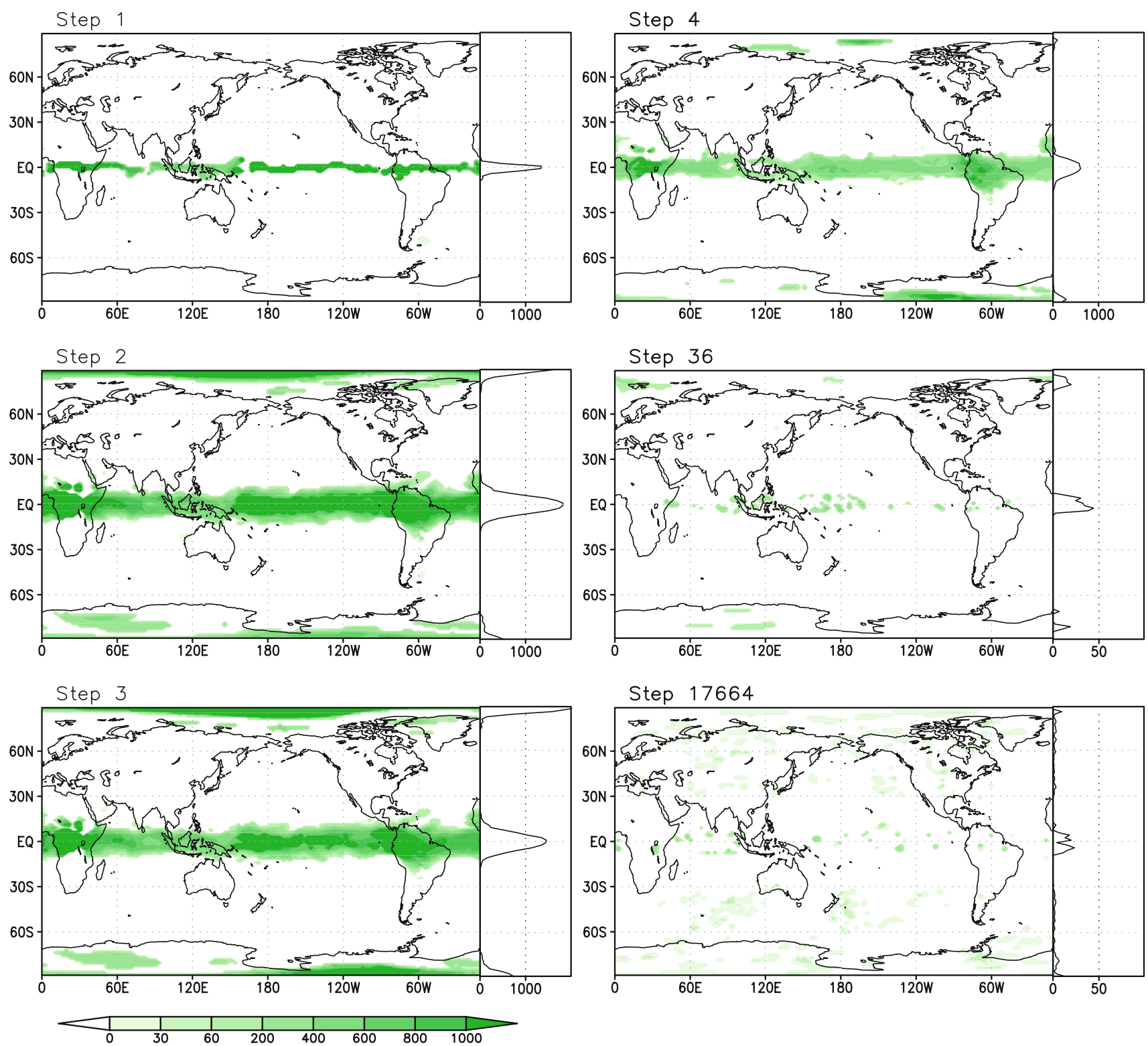

Fig. 6 As for Fig. 5, except for the $T_{\text {chg }}$ experiment

performances of the Zhang and Tiedtke schemes are different thereafter. By Step 36 in the $Z_{\text {chg }}$ experiment, CAPE intensity has decreased, although a maximum exceeding $400 \mathrm{~J} \mathrm{~kg}^{-1}$ is still located at the equator. In the $T_{\text {chg }}$ experiment, however, CAPE shows a relatively abrupt decrease to below $50 \mathrm{~J} \mathrm{~kg}^{-1}$, and deep convection only occurs locally at scattered sites. More importantly, most of the sites of deep convection are located on either side of the equator. By Step 17664 (Day 184), when the energy balance of the atmosphere has been achieved, CAPE distribution in the $Z_{\text {chg }}$ experiment (Fig. 5) is similar to that at Step 36. A strong single peak exceeding $400 \mathrm{~J} \mathrm{~kg}^{-1}$ is located at the equator, corresponding to the single ITCZ in Fig. 3c. In the $T_{\text {chg }}$ experiment (Fig. 6), however, there is little deep convection at the equator: most occurs on either side. The zonal-mean single peak of CAPE splits into double peaks with zonal mean intensities below $30 \mathrm{~J} \mathrm{~kg}^{-1}$, corresponding to the double ITCZ in Fig. 3d.

It is instructive to compare the distributions of CAPE and LCL with that of precipitation, as shown in Fig. 3. For this purpose, the evolutions of the zonal mean CAPE and ( $T-T_{\mathrm{d}}$; where $T$ is temperature and $T_{\mathrm{d}}$ is dew-point temperature) at 1,000 $\mathrm{hPa}$ are presented in Figs. 7 and 8, respectively, using the same layout as that employed in Fig. 3. Because the LCL is approximately proportional to the difference between $T$ and $T_{\mathrm{d}}$ at the surface, Fig. 8 can be considered a good representation of the distribution of LCL. In the experiments that employ Zhang's scheme (i.e., the 
Fig. 7 As for Fig. 3, except for CAPE. The color scale on the left is for $\mathbf{a}$ and $\mathbf{c}$; that on the right is for $\mathbf{b}$ and $\mathbf{d}$. Unit is $\mathrm{J} \mathrm{kg}^{-1}$ (a) $Z_{\text {ori }}$

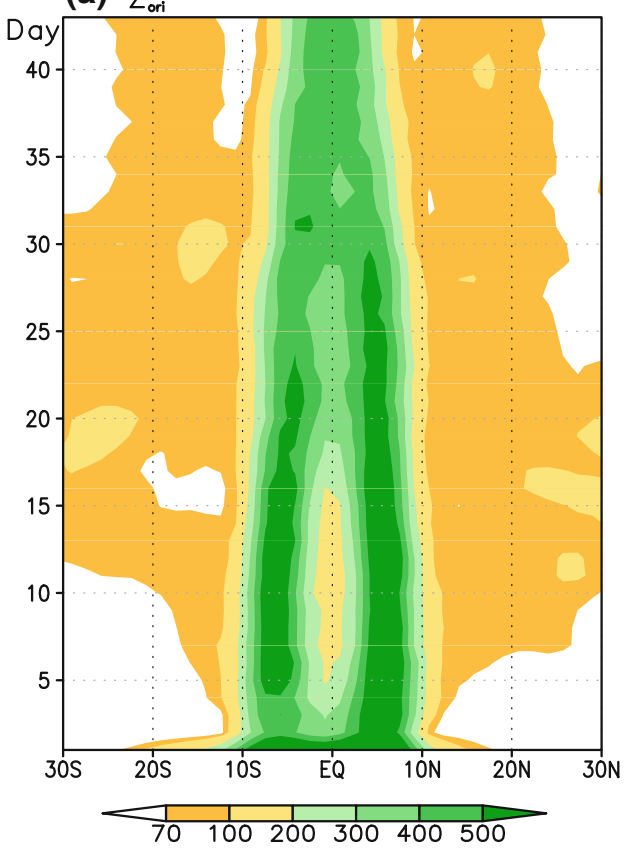

(c) $Z_{\text {cng }}$

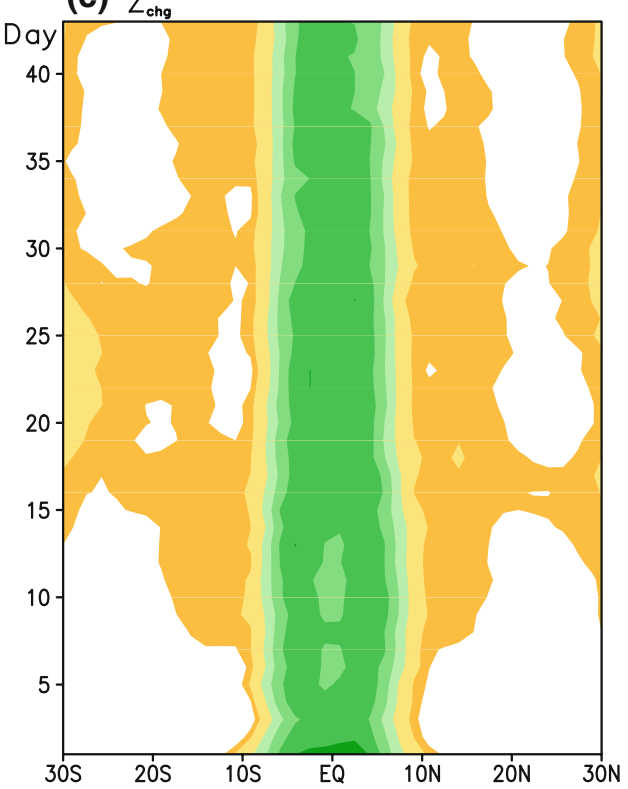

(b) $T_{\text {ori }}$

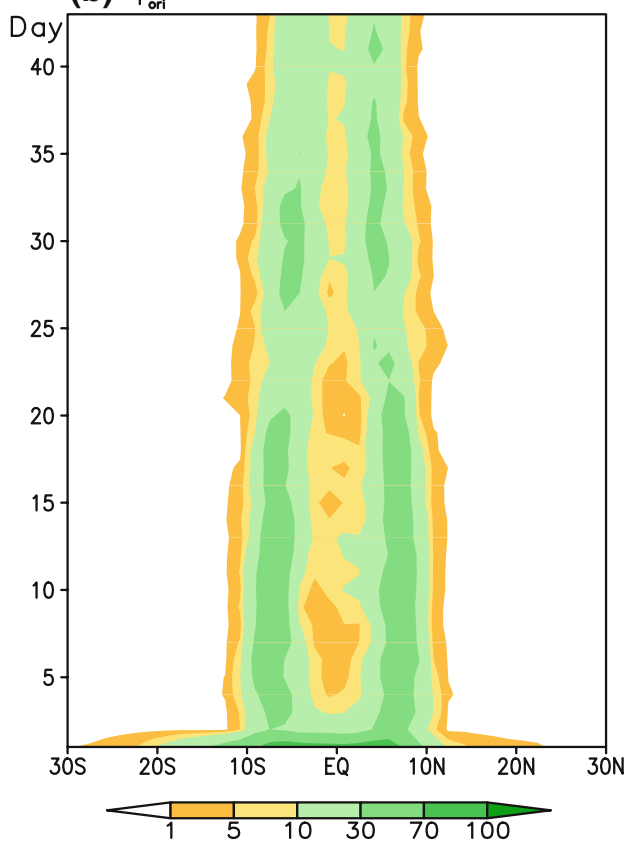

(d) $T_{\text {cho }}$

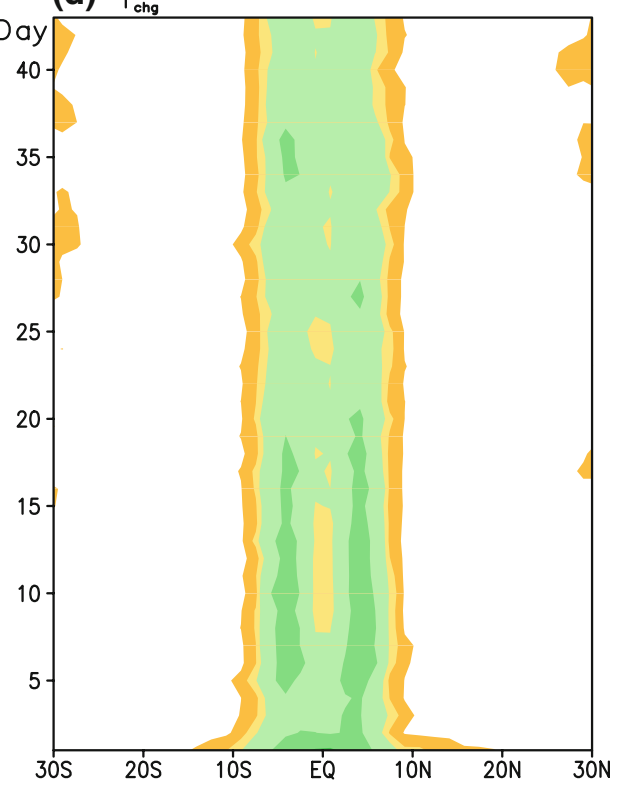

$Z_{\text {ori }}$ (Figs. 3a, 7a) and $Z_{\text {chg }}$ (Figs. 3c, 7c) experiments), the profile of CAPE exceeding $70 \mathrm{~J} \mathrm{~kg}^{-1}$ agrees well with precipitation because $70 \mathrm{~J} \mathrm{~kg}^{-1}$ is the threshold employed for triggering convective activity in Zhang's scheme.

It is important to note that in the $Z_{\text {ori }}$ experiment, in which two moisture peaks occur in the initial field, although there exist double-maximum CAPE and rainfall off the equator before Day 20, CAPE is weakened along the double ITCZ but intensified along the equator after Day 20 (Fig. 7a), while the intensity of rainfall remains largely unchanged (Fig. 3a). The two ITCZs approach the equator and merge into a single ITCZ at around Day 30.
Subsequently, rainfall intensifies along the single ITCZ. In the $Z_{\text {chg }}$ experiment, a single moisture maximum occurs in the initial field, and a strong single CAPE is associated with intense rainfall along the equator during the first few days (Figs. 7c, 3c). These results can be considered as the model response to the initial distributions of $q$ and $T$. From Day 5 to about Day 15, however, the equatorial single maximum CAPE and the corresponding rainfall split into double maxima off the equator. This event implies the existence of a mechanism, located away from the equator, which triggers convection. On Day 15, the double ITCZ starts to merge into a single ITCZ again. In the $Z_{\text {chg }}$ run, in 
Fig. 8 As for Fig. 7, except for the difference between temperature and dew-point temperature $\left(T-T_{\mathrm{d}}\right)$ at $1,000 \mathrm{hPa}$. Unit is ${ }^{\circ} \mathrm{C}$ (a) $Z_{\text {ori }}$

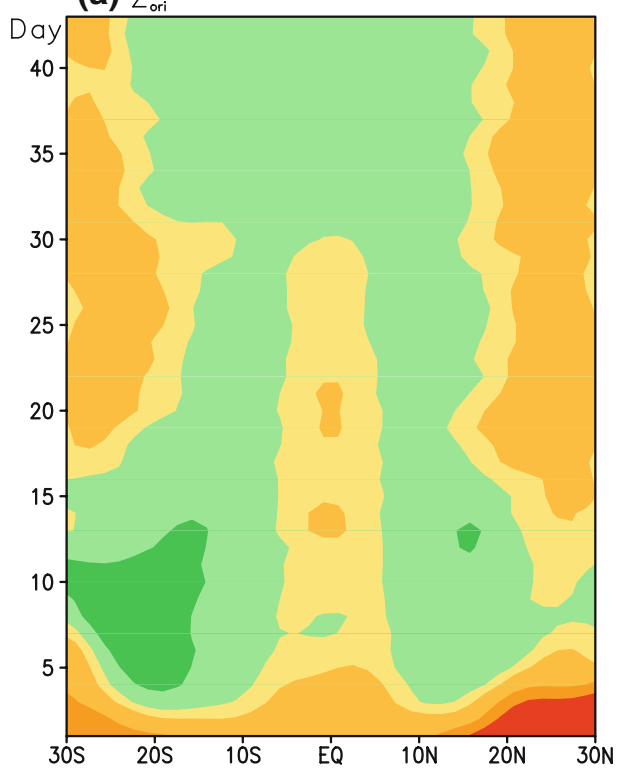

(c) $Z_{\text {chg }}$

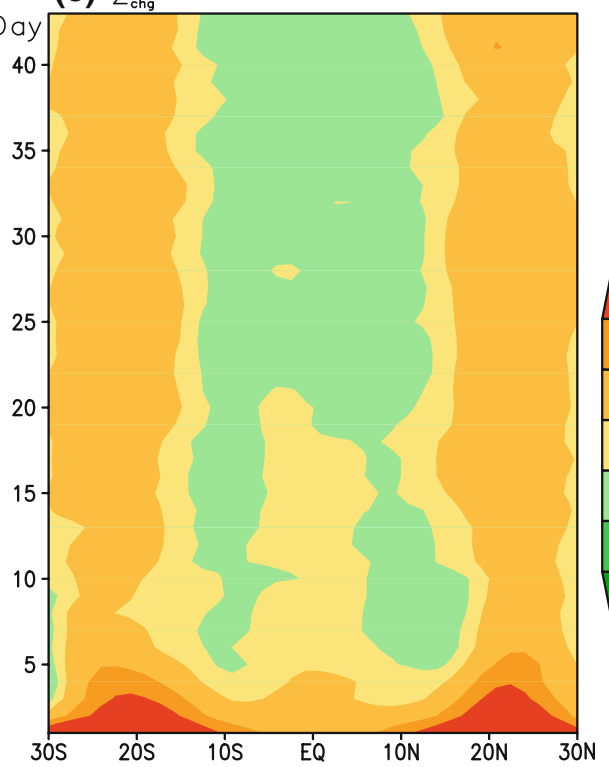

(b) $T_{\text {or }}$

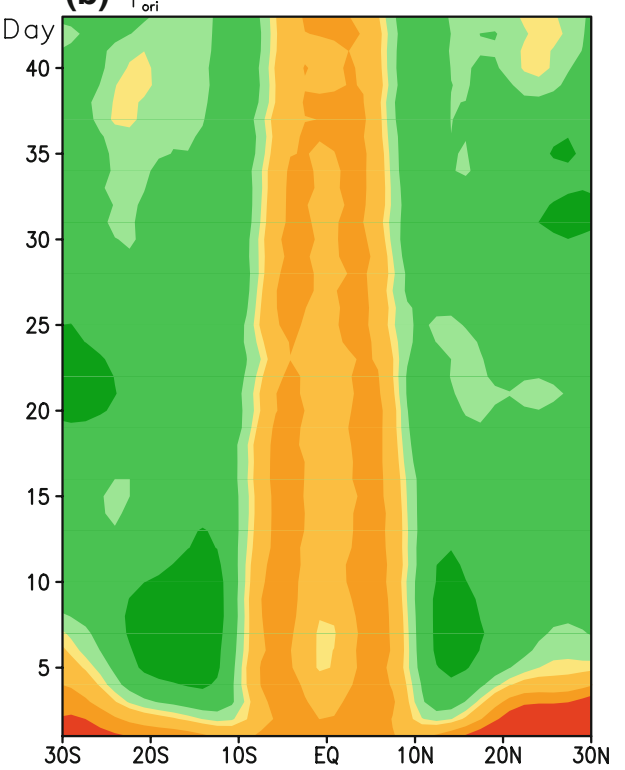

(d) $\mathrm{T}_{\mathrm{eng}}$

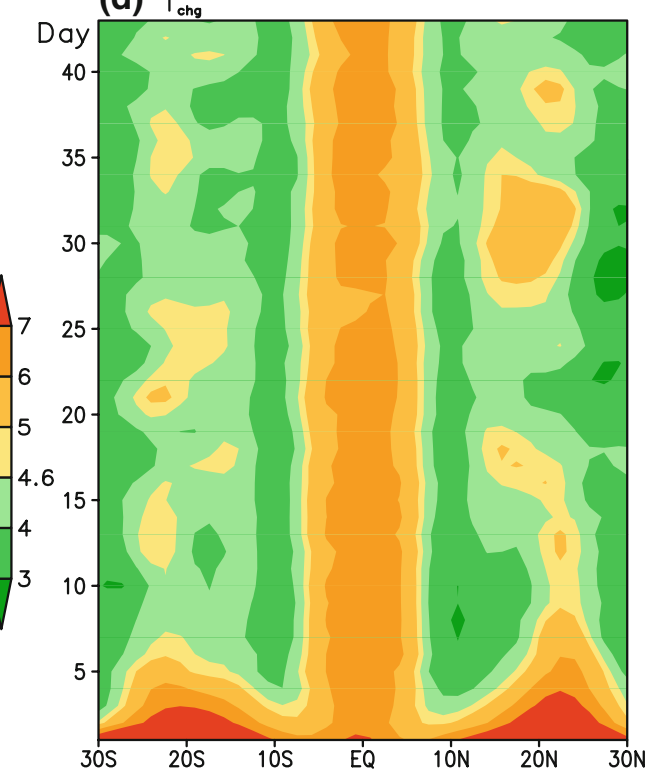

which there exists only a single maximum $q$ at the equator, the time required for the double ITCZ to merge into a single ITCZ is about half of that required in the $Z_{\text {ori }}$ run, in which there exist two peaks in $q$, straddling the equator. Nevertheless, the mergence of the double ITCZ into a single ITCZ indicates the existence of a mechanism at the equator that prevails over the off-equator mechanism mentioned above.

In the experiments employing the Tiedtke scheme, the configuration of CAPE in the experiments with initial double peaks in moisture off the equator (Fig. 7b) and with a single peak at the equator (Fig. 7d) agrees well with the corresponding configuration of precipitation (Fig. 3b, d). In the $T_{\text {ori }}$ run, there exists a double ITCZ from the beginning of integration, whereas in the $T_{\text {chg }}$ run a single CAPE maximum appears at the equator for the fist few days before evolving into a double ITCZ.

These findings represent the model response to the initial conditions during the first few days of the experiment. More importantly, the rapid establishment and persistence of double ITCZs in the two experiments again indicates the existence of a convection-triggering mechanism off the equator (Fig. 3b, d). Compared with the experiments that employ Zhang's scheme, the intensity of CAPE is very weak. Except for the very beginning of the $T_{\text {ori }}$ experiment (Fig. 7b), the daily mean CAPE along the ITCZ is less than $70 \mathrm{~J} \mathrm{~kg}^{-1}$, even during the first few days in the $T_{\text {chg }}$ experiment when a single ITCZ is maintained. For the 
CISK mechanism to operate, a strong CAPE (i.e. strong convective instability) is required to maintain heavy rainfall along the ITCZ. Thus, the combination of weak CAPE and strong rainfall along the ITCZ in the $T_{\text {ori }}$ and $T_{\text {chg }}$ experiments indicates that the existence of a double ITCZ cannot be explained in terms of the CISK mechanism.

\subsection{Evolution of $\left(T-T_{\mathrm{d}}\right)$ at the surface}

Figures 3, 5, and 6 show that deep convection at the equator occurs more readily when using Zhang's scheme than when using Tiedtke's scheme under the Control SST distribution; this difference reflects the choice of triggering thresholds. In the $T_{\text {chg }}$ experiment, in contrast, deep convection occurs more readily off the equator, along $5-10^{\circ} \mathrm{N}$ and $5-10^{\circ} \mathrm{S}$, than at the equator. Why does deep convection occur more readily at $5^{\circ} \mathrm{N}$ and $5^{\circ} \mathrm{S}$ than at the equator when using Tiedtke's scheme? The threshold for triggering convection in Tiedtke's scheme requires that the air parcel must overcome the negative buoyancy below the LCL. To achieve this, the lifted air parcel must be warmer than the environment, although containing less water vapor, as these conditions result in a lower LCL and deep convection. Here, we first diagnose in various experiments the height of the LCL, which is approximately proportional to the difference between $T$ and $T_{\mathrm{d}}\left(T-T_{\mathrm{d}}\right)$ at $1,000 \mathrm{hPa}$; in general, the smaller the value of $\left(T-T_{\mathrm{d}}\right)$ at the surface, the lower the LCL.
Figure 8 shows the evolution of the zonal mean surface wetness $\left(T-T_{\mathrm{d}}\right)$ in all experiments. In the tropics, the following prominent feature is common to all experiments before Day 20: the surface is dry along the equator compared with areas off the equator. This finding indicates the existence of a persistent atmospheric mechanism off the equator by which the in situ wet surface is sustained.

Figure 8 shows that distinct results are obtained using different parameterization schemes. In the $Z_{\text {ori }}$ experiment, the off-equator double minimum $\left(T-T_{\mathrm{d}}\right)$ belts merge into a single ITCZ at around Day 30 , whereas in the $Z_{\text {chg }}$ experiment the belts merge by Day 20. These findings are consistent with the evolution in rainfall (Fig. 3a, c) and CAPE (Fig. 7a, c). In contrast, in the experiment that employs Tiedtke's scheme, $\left(T-T_{\mathrm{d}}\right)$ is always larger at the equator than off the equator (Fig. 8b, d).

Because there exists little variation in surface temperature throughout the tropics $\left(10^{\circ} \mathrm{N}-10^{\circ} \mathrm{S}\right.$; data not shown), ( $T-T_{\mathrm{d}}$ ) is basically determined by the specific humidity of the environment. That is, increased water vapor leads to a reduction in $\left(T-T_{\mathrm{d}}\right)$ and lower LCL, meaning that a rising air parcel can more readily reach saturation. Figure $9 \mathrm{a}$ shows the evolution of the zonal mean specific humidity at the lowest model level $(\sigma=0.9911)$ during Day 1 from Steps 1 to 96 in the $T_{\text {chg }}$ experiment. The peak of the zonal mean specific humidity separates into double peaks from Step 12. There are two potential explanations for this change in water vapor: convergence of water vapor
Fig. 9 Evolution during Day 1 from time steps 1 to 96 in the $T_{\text {chg }}$ experiment of a zonal mean specific humidity at the lowest model level ( $\sigma=0.9911$, unit is $\mathrm{g} \mathrm{kg}^{-1}$ ), and b zonal mean upward surface latent-heat flux (SLHF, unit is $\mathrm{W} \mathrm{m}^{-2}$ )

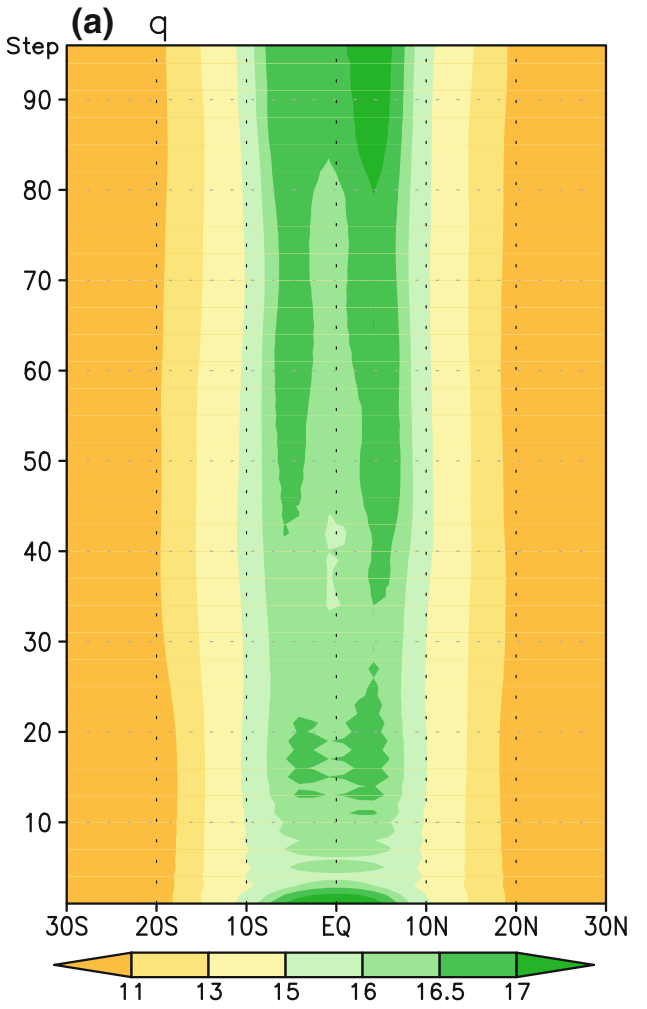

(b) SLHF

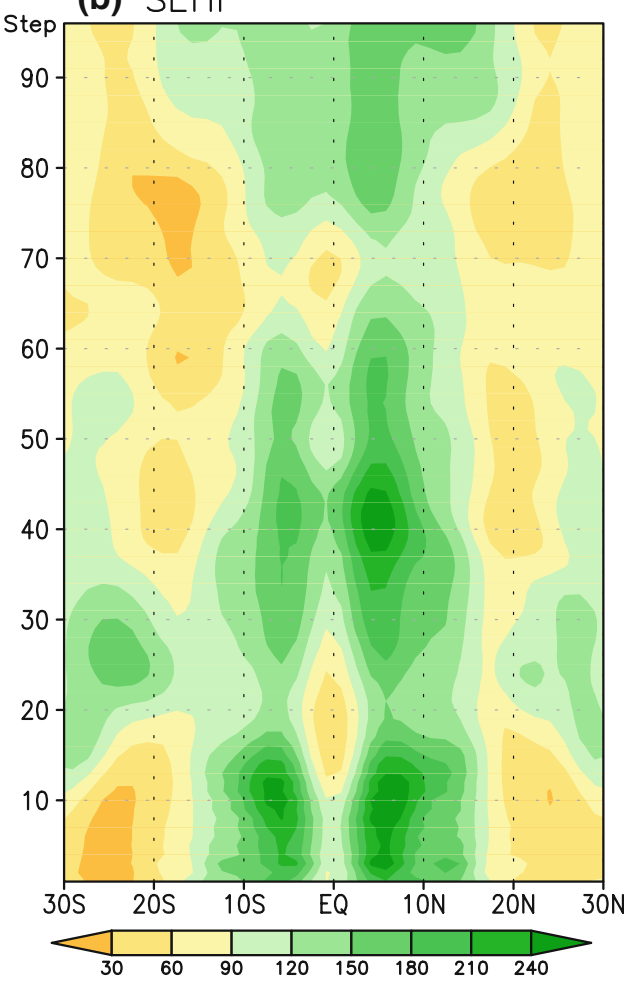


due to horizontal advection, and local evaporation. Because all of the experiments are integrated in the aqua planet, the water vapor evaporated from the sea surface should be considered. Figure $9 \mathrm{~b}$ shows the evolution of zonal mean upward surface latent heat flux (SLHF) during Day 1. From the first step, SLHF shows clear double peaks straddling the equator, where more water vapor enters the atmosphere from the underlying ocean surface than occurs over the equator. This explains why the specific humidity at the lowest model level changes from a single peak to a double peak after several steps.

The surface exchange of moisture between the atmosphere and ocean is proportional to SLHF, which is treated in SAMIL using the following bulk dynamic formulation:

$$
\mathrm{SLHF}=\rho_{\mathrm{A}} L|\mathbf{V}| C_{\mathrm{E}} \Delta q
$$

where $\rho_{\mathrm{A}}$ is atmospheric surface density, $L=2.501 \times$ $10^{6} \mathrm{~J} \mathrm{~kg}^{-1}$ is the latent heat of evaporation, $|\mathbf{V}|$ is the absolute value of the wind vector at the lowest model level, and $C_{\mathrm{E}}$ is the moisture transfer coefficient. As discussed by
Businger et al. (1971), the ratio of the momentum transfer coefficient to the moisture transfer coefficient is 0.74 in the neutral limit. Thus,

$C_{\mathrm{E}}=C_{\mathrm{D}} / 0.74$

where $C_{\mathrm{D}}$ is the momentum transfer coefficient or the drag coefficient. Furthermore,

$\Delta q=\left(q_{\mathrm{S}}-q_{\mathrm{A}}\right)$

where $q_{\mathrm{s}}$ is the saturated specific humidity at the sea surface and $q_{\mathrm{A}}$ is the specific humidity of the lowest model level.

Because the SST is fixed and $q_{\mathrm{A}}$ splits into double peaks with smaller values at the equator, $\triangle q$ maintains a single peak at the equator during the entire integration. $\rho_{\mathrm{A}}$ can be considered a constant. The variables responsible for variation in SLHF are $C_{\mathrm{D}}$ and $|\mathbf{V}|$; their evolutions during Day 1 are shown in Fig. 10a and b, respectively. From the first step, the maximum values of $C_{\mathrm{D}}$ and $|\mathbf{V}|$ are located on either side of the equator, between latitudes of 5 and $10^{\circ}$. (a) $C_{0}$

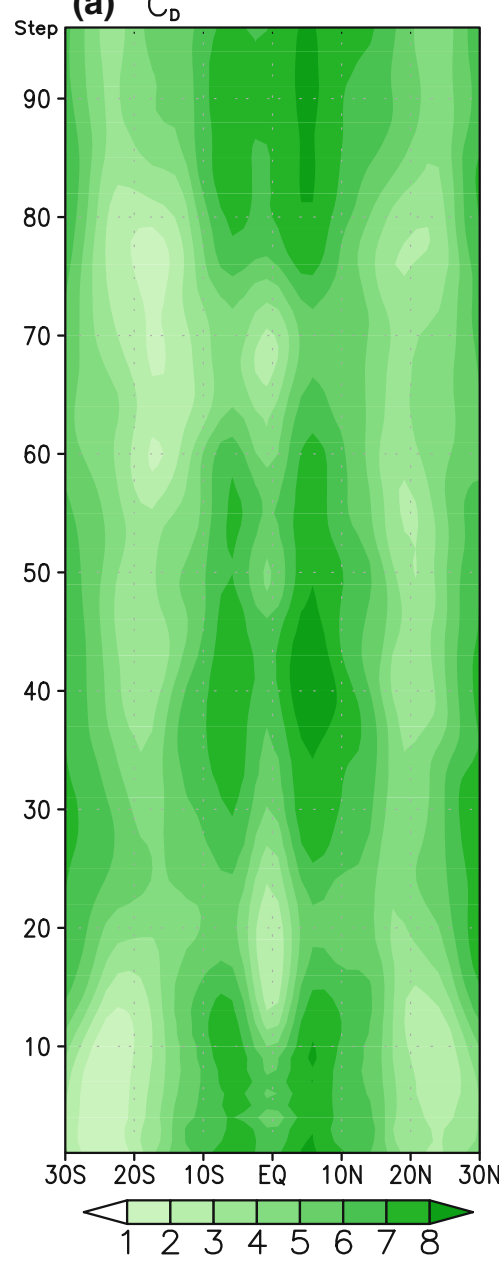

(b)

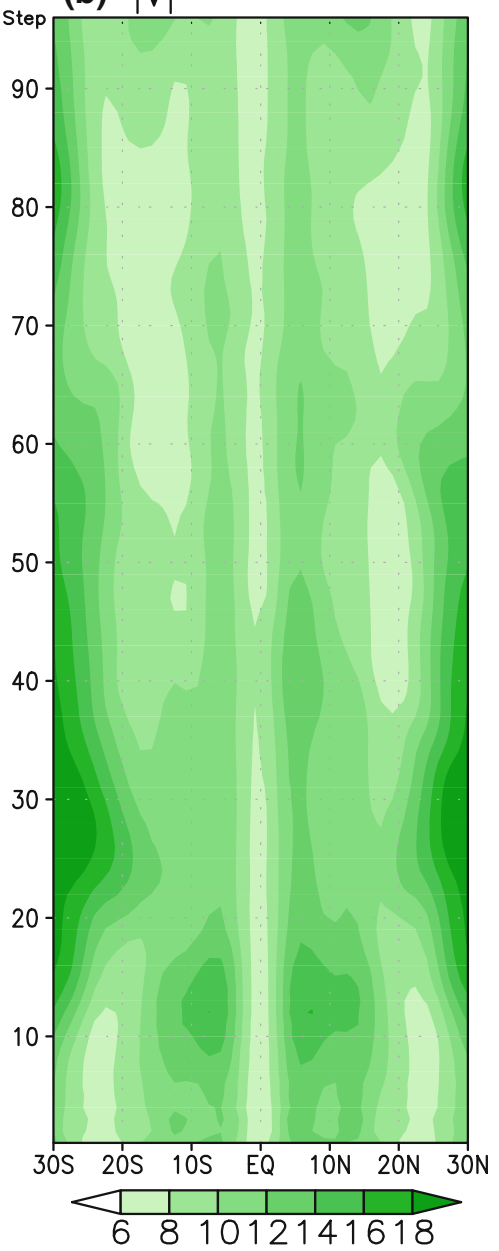

(c) $s_{n}$

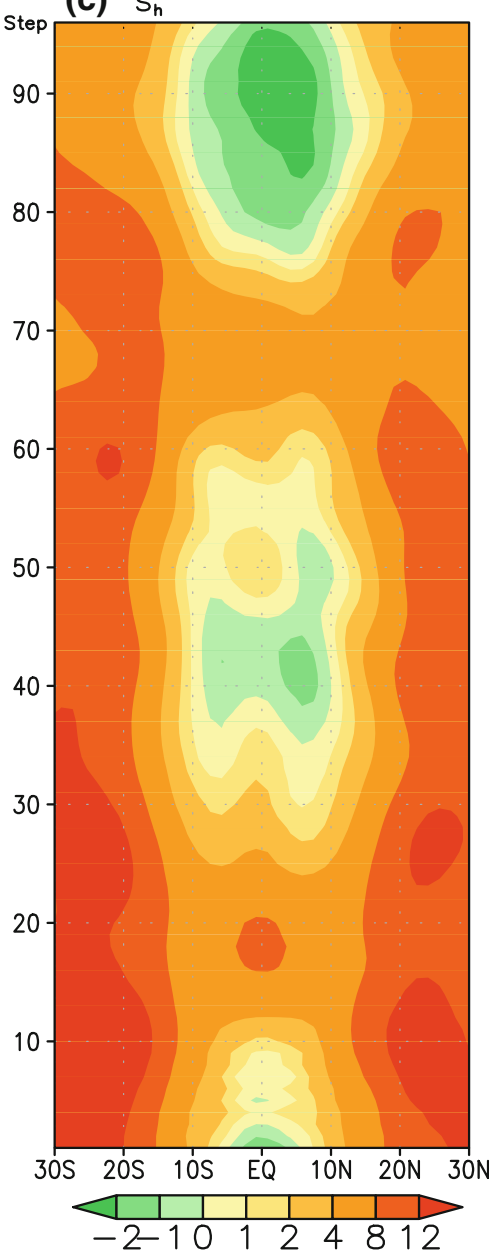

Fig. 10 Evolution during Day 1 from time steps 1 to 96 in the $T_{\text {chg }}$ experiment of a the drag coefficient (unit is $10^{-4}$ ), b wind velocity (unit is $\mathrm{m} \mathrm{s}^{-1}$ ), and $\mathbf{c}$ the stability $\left(\mathrm{s}_{h}\right)$ at the lowest model level 
According to Tiedtke et al. (1979) and Louis (1979), the drag coefficient is a function of $|\mathbf{V}|$ and thermal stability $\left(s_{\mathrm{h}}\right) . s_{\mathrm{h}}<0$ denotes an unstably stratified surface layer, and $s_{\mathrm{h}}>0$ a stably stratified surface layer. Figure 10c shows the evolution of $s_{\mathrm{h}}$ during Day 1 from Steps 1 to 96 . The surface layer of the atmosphere in the tropics $\left(10^{\circ} \mathrm{N}-10^{\circ} \mathrm{S}\right)$ during Day 1 is unstably stratified from the beginning.

Figure 11 shows variation in the drag coefficient in terms of $|\mathbf{V}|$ and $s_{\mathrm{h}}$. When wind speed exceeds $3 \mathrm{~m} / \mathrm{s}$, the drag coefficient is roughly proportion to the wind speed, regardless of the type of stratification in the surface layer. Thus, in the $T_{\text {chg }}$ experiment the drag coefficient is 0.0007 at the equator where $|\mathbf{V}|=7 \mathrm{~m} / \mathrm{s}$, while it reaches 0.00095 at $5^{\circ} \mathrm{N}$ and $5^{\circ} \mathrm{S}$, where $|\mathbf{V}|=15 \mathrm{~m} / \mathrm{s}$.

Therefore, as discussed above, $|\mathbf{V}|$ is the main factor influencing variations in evaporation at the sea surface. $|\mathbf{V}|$ affects evaporation in two ways: (1) higher surface wind speed contributes to the evaporation of more water vapor from the ocean to the atmosphere, and (2) because the surface layer is an unstably stratified layer, high wind speed can lead to an intensification of turbulent diffusivity, leading in turn to a further increase in sea surface evaporation.

Figure 12 shows the evolution of the absolute values of zonal wind and meridional wind at the lowest model level from Steps 1 to 96. There exists a pronounced calm belt at the equator from Step 1. The maxima in lul along the belts $5-10^{\circ} \mathrm{N}$ and $5-10^{\circ} \mathrm{S}$ are clear and persistent. In contrast, the double peaks in $\mathrm{lvl}$ are not persistent and of lower intensity than the peaks in lul. Thus, the occurrence of maximum evaporation on either side of the equator (between latitudes of $5^{\circ}$ and $10^{\circ}$ ) rather than at the equator is attributed mainly to peaks in lul being sustained along these off-equatorial belts and the occurrence of a calm belt at the equator.

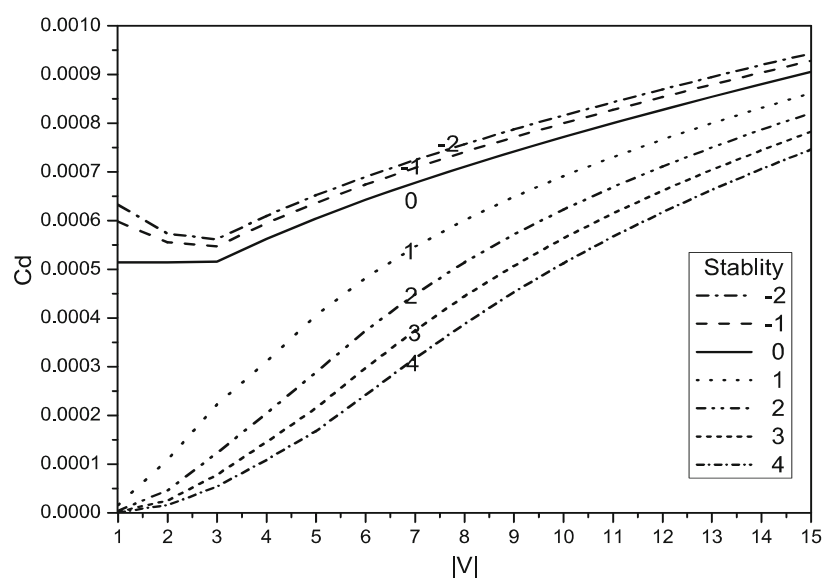

Fig. 11 Drag coefficient $\left(C_{\mathrm{d}}\right)$ versus wind velocity $|V|$ (unit is $\mathrm{m} \mathrm{s}^{-1}$ ) for different stabilities $s_{\mathrm{h}}$

\section{Evaporation-wind feedback versus cisk}

As stated above, two factors are responsible for the ITCZ splitting from a single to double form in the $T_{\text {chg }}$ experiment: stronger evaporation on the sea surface off the equator, and varying latitudinal distribution of the threshold for triggering convection. Because there exists a calm belt at the equator, the stronger wind speed along the belts $5-10^{\circ} \mathrm{N}$ and $5-10^{\circ} \mathrm{S}$ results in greater in situ evaporation, thereby increasing the surface air moisture and lowering the LCL. Figure 13 shows the evolution of specific humidity and its horizontal divergence at the lowest model level ( $\sigma=0.9911)$ in the $Z_{\text {chg }}$ and $T_{\text {chg }}$ experiments. In the latter experiment, the maximum $q$ appears along the belts $5-10^{\circ} \mathrm{N}$ and $5-10^{\circ} \mathrm{S}$ (Fig. 13b), in good correspondence with the distributions of strong zonal wind (Fig. 12a) and small values of $\left(T-T_{\mathrm{d}}\right)$ (Fig. 8d). The large amount of moisture along these two belts is transferred equatorward by near-surface meridional advection in association with Hadley circulation, resulting in two belts of strong convergence of moisture flux near $5^{\circ} \mathrm{N}$ and $5^{\circ} \mathrm{S}$ (Fig. 13d), on the near-equator sides of the belts of maximum $q$. Convection occurs relatively readily in these regions, leading to an intensification of diabatic heating.

According to Hoskins (1987), diabatic heating in the tropics is balanced mainly by adiabatic cooling associated with ascent. In such areas, upward velocity is stronger than that at the equator. Furthermore, according to the continuity of the atmosphere, the maximum convergence in the lower layers will be further intensified near $5^{\circ} \mathrm{N}$ and $5^{\circ} \mathrm{S}$, as demonstrated in Fig. 13d. Use of the Tiedtke convection threshold induces a positive feedback between convective precipitation and surface moistening associated with surface evaporation off the equator, and the double ITCZ in the $T_{\text {chg }}$ experiment forms (Fig. 3d) via the evaporationwind feedback mechanism.

Figure 13a and $\mathrm{c}$ shows the specific humidity and horizontal divergence of water vapor flux at the lowest model level in the $Z_{\text {chg }}$ experiment, respectively. In contrast to the $T_{\text {chg }}$ experiment, the maximum convergence of water flux is located over the equatorial region from the very beginning (Fig. 13c), while the specific humidity shows a double maximum before Day 16 but a single maximum at the equator thereafter (Fig. 13a), consistent with the evolution of prominent single ITCZ and CAPE in Figs. 3c, 5, 7c, and $8 \mathrm{c}$. These results indicate that during the early stage of the $Z_{\text {chg }}$ experiment, both the evaporation-wind feedback mechanism and the CISK mechanism co-exist in the model atmosphere. However, because CAPE along the equator exceeds $400 \mathrm{~J} \mathrm{~kg}^{-1}$ (Fig. 7c) and the corresponding largescale horizontal convergence of moisture flux near the surface (Fig. 13c) is very strong, the double $q$-maximum off the equator eventually merges into a single maximum 
Fig. 12 Evolution from Step 1 to 96 in the $T_{\text {chg }}$ experiment of the absolute value of a zonal wind $u$ and $\mathbf{b}$ meridional wind $v$ at the lowest model level $(\sigma=0.9911)$. Unit is $\mathrm{m} \mathrm{s}^{-1}$ (a) $|u|$

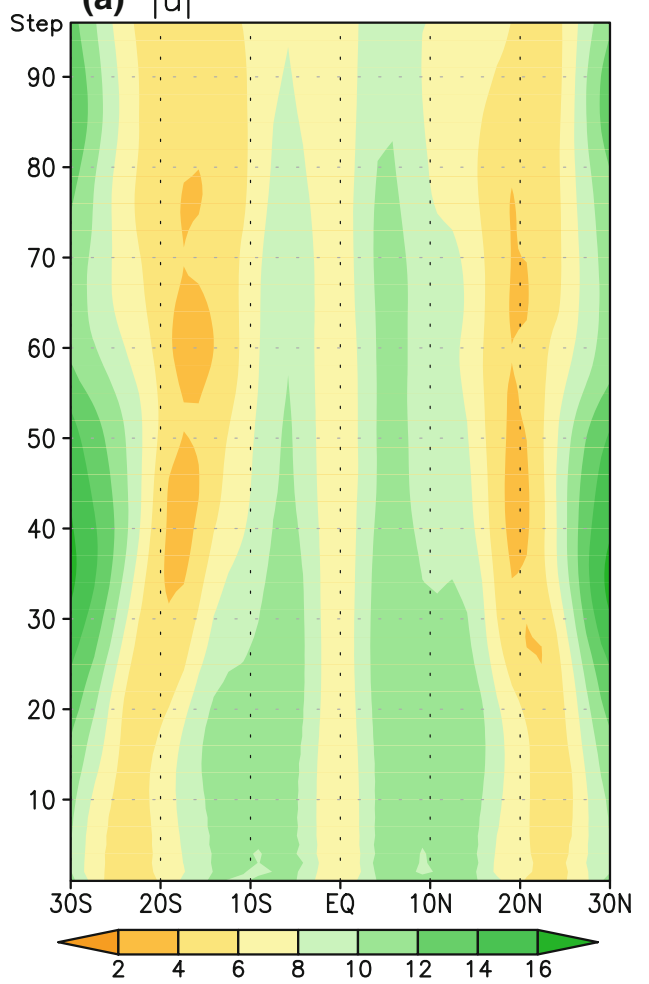

(b) $|v|$

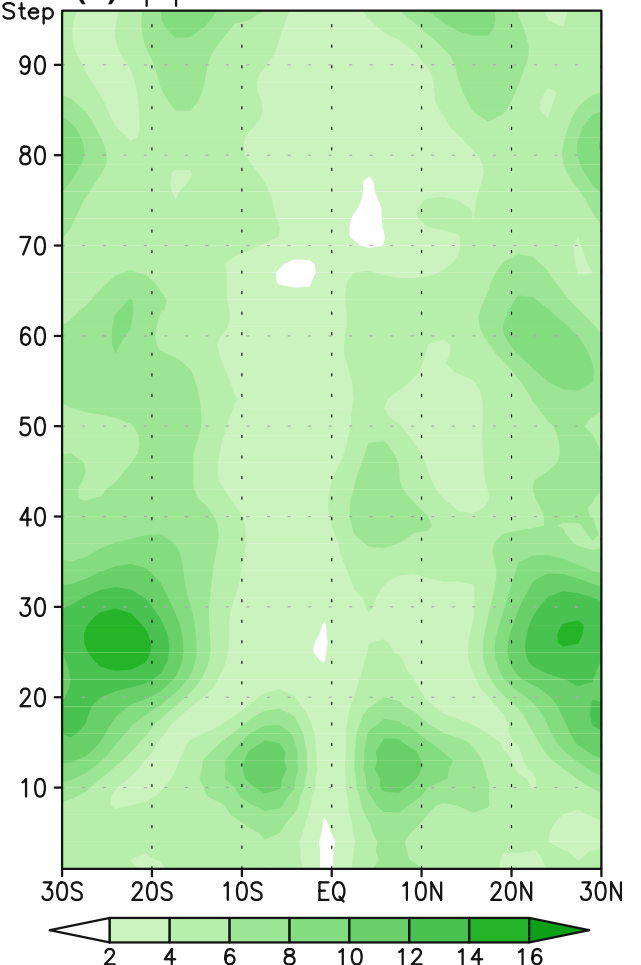

along the equator. We infer that the ultimate occurrence of a single ITCZ peak at the equator eventuates because in this $Z_{\text {chg }}$ experiment the CISK mechanism is strong enough to overwhelm the wind-evaporation feedback mechanism.

To verify the above hypothesis, we performed another experiment $\left(Z_{\text {chg_half }}\right)$ that involved reducing by $50 \%$ the amount of convective condensation latent heat released in the equatorial zone between $2.5^{\circ} \mathrm{N}$ and $2.5^{\circ} \mathrm{S}$ in the $Z_{\text {chg }}$ experiment (i.e., the amount of convective heating is reduced by $50 \%$ at each time step). By doing so, the CISK mechanism at the equator is relaxed to a great extent. As demonstrated in Fig. 14a and in accordance with a single equatorial maximum $q$ in the initial field, a single CAPE maximum occurs at the equator only for the first few days, showing a rapid decrease in intensity. By Day 5, CAPE over the equator is already below $200 \mathrm{~J} \mathrm{~kg}^{-1}$, less than $50 \%$ of that in the $Z_{\mathrm{chg}}$ experiment (Fig. 7c), and its maximum peak is split into a double peak off the equator with intensities exceeding $400 \mathrm{~J} \mathrm{~kg}^{-1}$. This finding indicates weakening of CISK at the equator and its intensification off the equator.

At the surface, high values of $\left(T-T_{d}\right)$ are maintained at the equator from the very beginning, but during the first several days the values decrease either side of the equator along the belts near $10^{\circ}$, thereafter maintaining minimum values below $4.6^{\circ} \mathrm{C}$ (Fig. 14b). This finding indicates operation of the evaporation-wind feedback mechanism from the early stages of model integration. This feature, together with the operation of CISK in the free atmosphere after Day 5, results in the occurrence of a double ITCZ in the $Z_{\text {chg_half }}$ experiment, which is represented by the double belt of intense precipitation shown in Fig. 14c.

The above results support our above hypothesis that when latent heating at the equator is halved, the in situ CISK mechanism is weakened. As a consequence, horizontal convergence within the boundary layer associated with Ekman pumping at the equator is also weakened. Because there is no supply of abundant water vapor, convection over the equator is suppressed. Over time, the effect of evaporation-wind feedback off the equator becomes dominant, which also results in the CISK mechanism shifting from the equator to off-equator. Consequently, the double ITCZ pattern appears.

\section{Conclusion and discussion}

In this study, we examined the performances of different cumulus convection parameterizations in a zonally symmetric aqua planet with latitudinally varying distributions of SST and solar angle. We used precipitation to represent the ITCZ, and found a single ITCZ in the experiment that employed Zhang's scheme and a double ITCZ when Tiedtke's scheme was used.

As mentioned in the Sect. 1, Chao and Chen (2004) hypothesized that the more stringent the criterion employed 
Fig. 13 Evolution of the zonal mean specific humidity in the $Z_{\text {chg }}$ experiment a and $T_{\text {chg }}$ experiment $\mathbf{b}$ (unit is $\mathrm{g} \mathrm{kg}^{-1}$ ), and divergence of vapor flux $\nabla \cdot\left(\vec{V} q g^{-1}\right)$ in the $Z_{\text {chg }}$ experiment $\mathbf{c}$ and $T_{\text {chg }}$ experiment $\mathbf{d}$ [unit is $10^{-7} \mathrm{~g}$ $\left.\left(\mathrm{s} \mathrm{cm}^{2} \mathrm{hPa}\right)^{-1}\right]$ at the lowest model level $(\sigma=0.9911)$ from Day 1 to Day 19 (a)
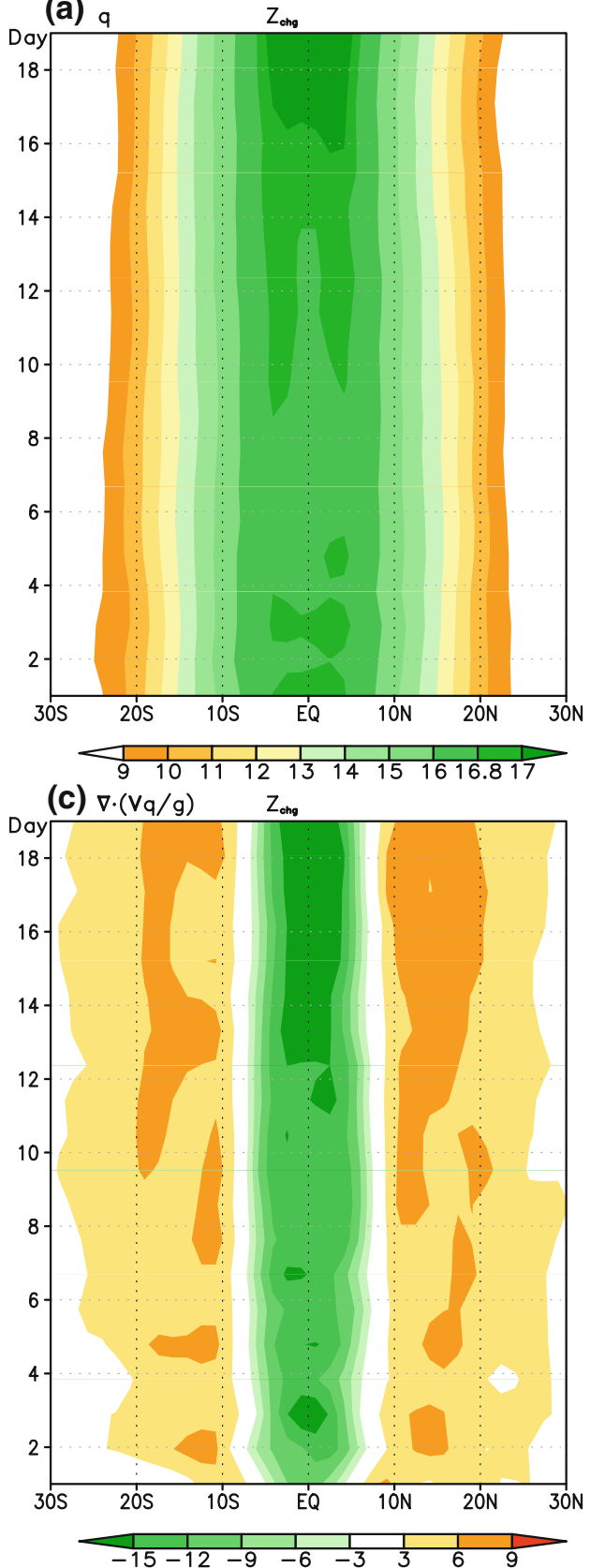
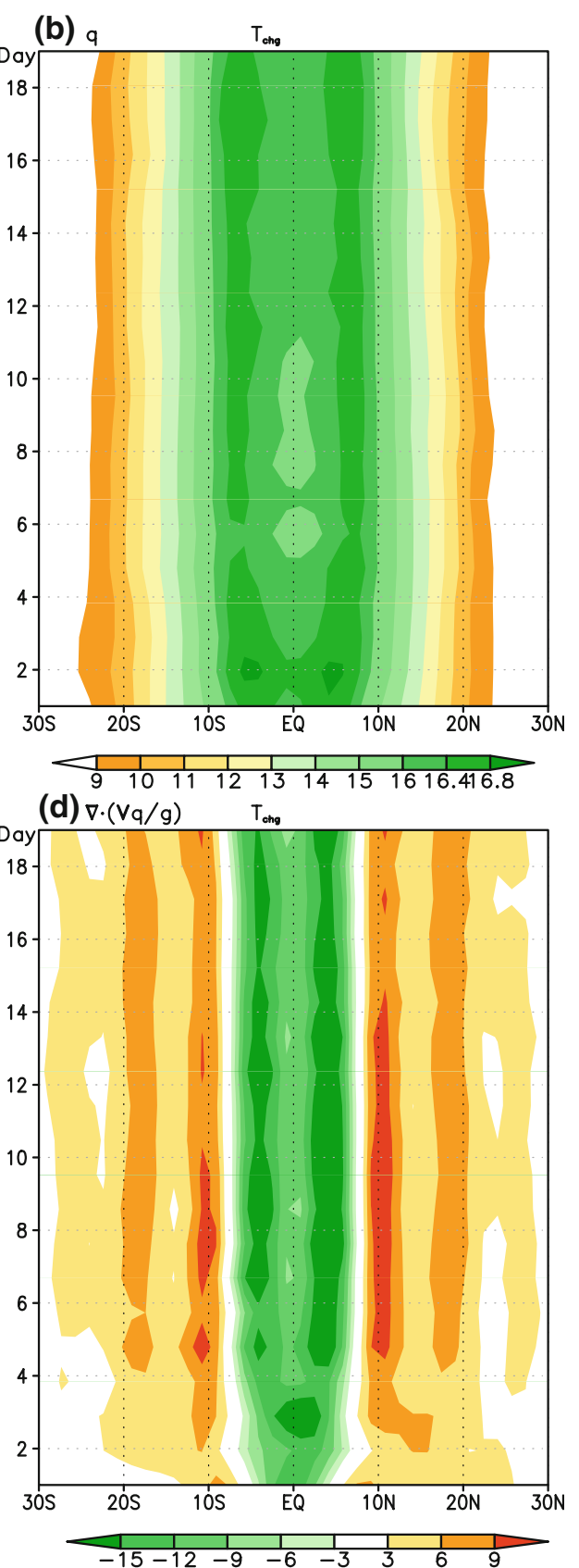

for convection to occur, the more likely the ITCZ would be concentrated in a smaller area on the equator, resulting in a single ITCZ. However, our results show that the threshold for triggering convection in Tiedtke's scheme is more stringent than that in Zhang's scheme. A double ITCZ develops in experiments based on Tiedtke's scheme, whereas a single ITCZ exists in the experiments based on Zhang's scheme. These results are inconsistent with Chao and Chen's hypothesis. Our experimental results demonstrate that the formation of a double ITCZ in experiments based on Tiedtke's scheme is not solely due to the choice of cumulus convection parameterization: it also depends on latitudinal variations in evaporation at the boundary layer. Such variations are caused mainly by latitudinal variations in zonal wind speed, which affects the distribution of evaporation via the evaporation-wind feedback mechanism.

In the experiments based on Zhang's scheme, CAPE and the horizontal convergence of moisture flux near the surface are maximized over the equatorial zone. Thus, convection tends to occur at the equator via the CISK mechanism, and maximum precipitation is maintained at the equator.

The results of the current study reveal that the application of Zhang's scheme favors the development of a single 
Fig. 14 Evolution of zonal mean CAPE a, $T-T_{\mathrm{d}} \mathbf{b}$, and precipitation $\mathbf{c}$ from Day 1 to Day 43 in the $Z_{\text {chg_half }}$ experiment. Units are $\mathrm{J} \mathrm{kg}^{-1}, \mathrm{~K}$, and $\mathrm{mm} \mathrm{day}^{-1}$, respectively

\section{(a) $\mathrm{CAPE}$}

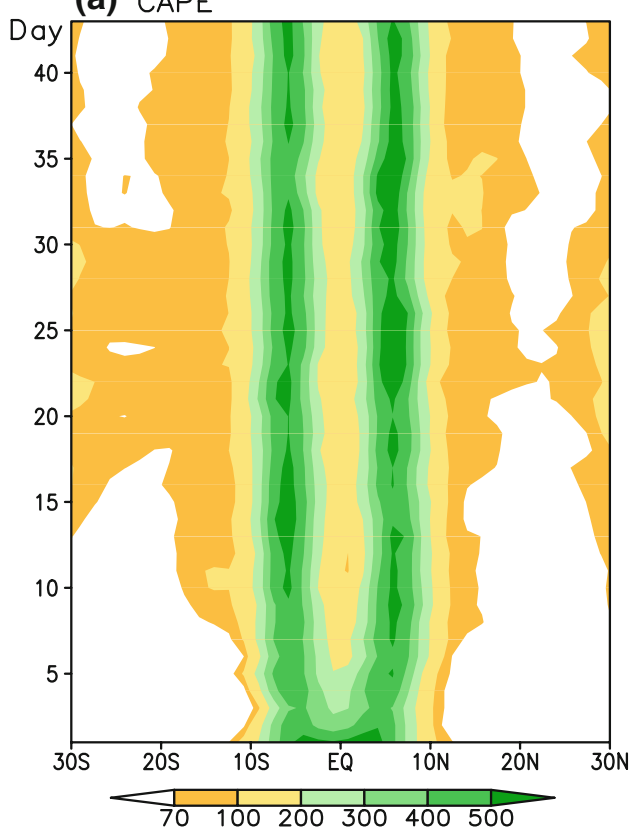

(c) Pre.

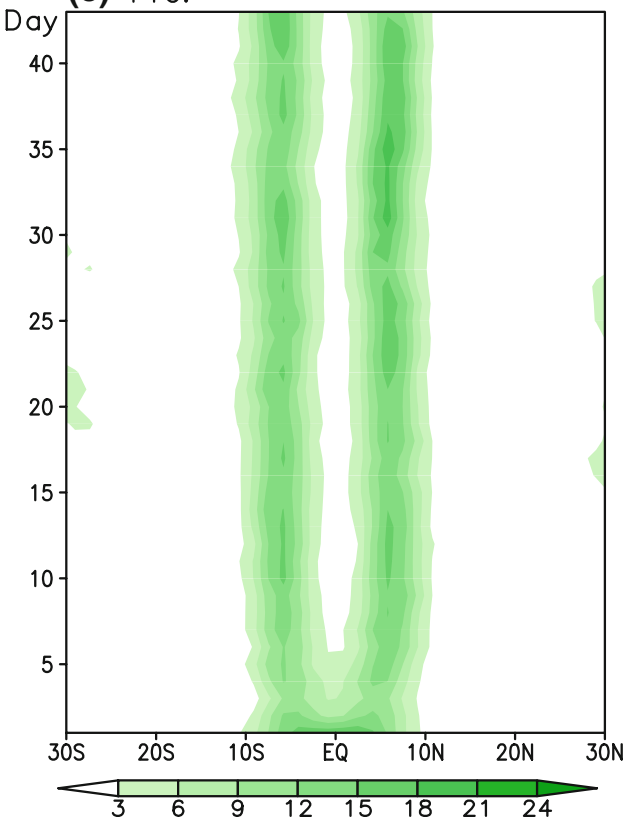

(b) $T-T_{d}$

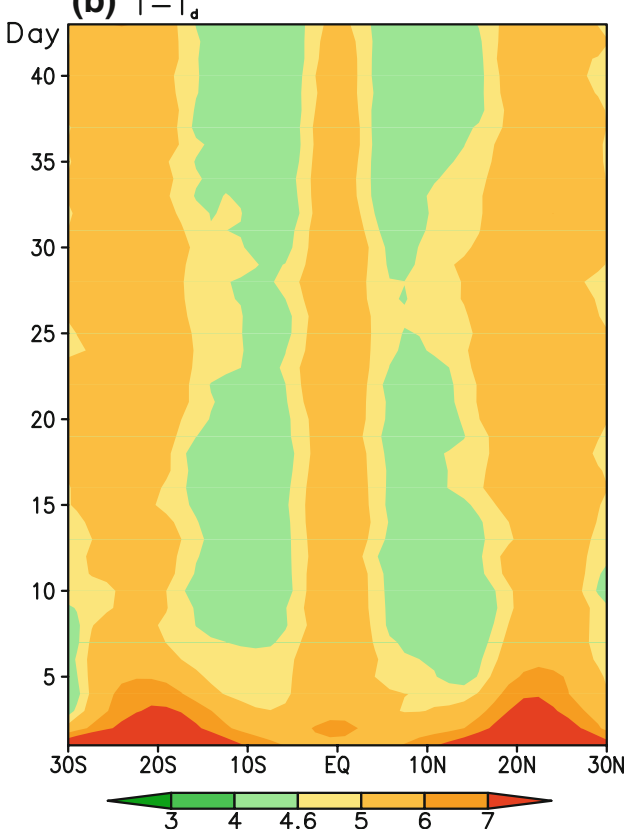

ITCZ along the equator, whereas the use of the Tiedtke scheme favors the formation of a double ITCZ off the equator. This finding is obtained under a specific Control SST distribution during the spring season. In fact, as demonstrated in Fig. 1, a change in the SST to some extreme distributions may produce single or double ITCZs regardless of the employed convective parameterization scheme. Therefore, our conclusions are conditional, and the validity of their application to other seasons with different SST distributions requires further study.
Both CISK and the wind-evaporation feedback mechanism can coexist in the real atmosphere as well as in models. Therefore, either a single or double ITCZ can develop even in a model that employs a specific convective parameterization scheme, depending on which mechanism prevails and what kind of SST distribution eventuates. As shown in Figs. 3, 7, and 13, a single ITCZ persists at the equator when the CISK mechanism is strong in Zhang's scheme, whereas a double-ITCZ pattern appears (Fig. 14) when CISK is relaxed and evaporation-wind feedback 
prevails. This finding suggests that model performance might be further improved by the appropriate choice of thresholds and coefficients in the convective parameterization scheme.

Acknowledgments The authors would like to thank Dr. Kun Liu for introducing the cumulus convection schemes, and Dr. JiangYu Mao and Yongjun Zheng for helpful discussions. Many constructive suggestions from Dr. Schneider and two anonymous reviewers led to significant improvements in the manuscript. This research was jointly supported by State Key Basic Research (grant 2006CB403607) and the NSFC (grants 40821092, 40875034, 40810059005, and 40523001).

Open Access This article is distributed under the terms of the Creative Commons Attribution Noncommercial License which permits any noncommercial use, distribution, and reproduction in any medium, provided the original author(s) and source are credited.

\section{References}

Arakawa A (2004) The cumulus parameterization problem: past, present, and future. J Clim 17:2493-2525

Arakawa A, Schubert WH (1974) Interaction of a cumulus cloud ensemble with the large-scale environment, part I. J Atmos Sci 31:674-701

Bjerknes J, Allison LJ, Kreins ER, Godshall FA, Warnecke G (1969) Satellite mapping of the Pacific tropical cloudiness. Bull Am Meteor Soc 50:313-322

Businger JA, Wyngaard JC, Izumi Y, Bradley EF (1971) Flux-profile relationships in the atmospheric surface layer. J Atmos Sci 28:181-189

Chao WC, Chen B (2004) Single and double ITCZ in an aqua-planet model with constant sea surface temperature and solar angle. Clim Dyn 22:447-459

Charney JG (1971) Tropical cyclogenesis and the formation of the ITCZ. In: Reid WH (ed) Mathematical problems of geophysical fluid dynamics. Am Math Soc 13:355-368

Charney JG, Eliassen A (1964) On the growth of hurricane depression. J Atmos Sci 21:68-75

Edwards JM, Slingo A (1996) A studies with a flexible new radiation code. I: choosing a configuration for a large 2 scale model. Q J R Meteorol Soc 122:689-720

Hayashi YY, Sumi A (1986) The 30-40 day oscillation simulated in an "Aqua-planet" model. J Meteorol Soc Jpn 64:451-467

Hess PG, Battisti DS, Rasch PJ (1993) Maintenance of the intertropical convergence zones and the large-scale tropical circulation on a water-covered Earth. J Atmos Sci 50:691-713

Holton JR, Wallace JM, Young JA (1971) On boundary layer dynamics and the ITCZ. J Atmos Sci 28:275-280

Hoskins BJ (1987) Dignosis of forced and free variability in the atmosphere. In: Cattle $\mathrm{H}$ (ed) Atmospheric and Oceanic Variability. Royal Meteorological Society, New York, pp 57-73
Hubert LF, Krueger AF, Winston JS (1969) The double intertropical convergence zone-fact or fiction? J Atmos Sci 26:771-773

Kirtman BP, Schneider EK (2000) A spontaneously generated tropical atmospheric general circulation. J Atmos Sci 57:20802093

Kuo HL (1974) Further studies of the parameterization of the influence of cumulus convection on large-scale flow. J Atmos Sci 31:1232-1240

Lin JL (2007) The double-ITCZ problem in IPCC AR4 Coupled GCMs: ocean-atmosphere feedback analysis. J Clim 20:44974525

Lindzen RS (1974) Wave-CISK in the tropics. J Atmos Sci 31:156179

Louis JF (1979) A parametric model of vertical eddy fluxes in the atmosphere. Bound Lay Meteor 17:187-202

Manabe S, Smagorinsky J, Strickler RF (1965) Simulated climatology of a general circulation model with a hydrologic cycle. Mon Weather Rev 93:769-798

Neale RB, Hoskins BJ (2000a) A standard test for AGCMs and their physical parameterizations. I: the proposal. Atmos Sci Lett 1:101-107

Neale RB, Hoskins BJ (2000b) A standard test for AGCMs and their physical parameterizations. II: results for The Met. Office Model. Atmos Sci Lett 1:108-114

Numaguti A, Hayashi YY (1991) Behavior of cumulus activity and the structures of circulations in an "Aqua Planet" model part II: eastward-moving planetary scale structure and the intertropical convergence zone. J Meteor Soc Jpn 69:563-579

Song XL (2005) The performances of two typical mass flux-type schemes in the climate modeling. Ph.D. thesis, Institute of Atmospheric Physics, Chinese Academy of Sciences, Beijing (in Chinese)

Sumi A (1992) Pattern formation of convective activity over the aquaplanet with globally uniform sea-surface temperature (SST). J Meteor Soc Jpn 70:855-876

Tiedtke M (1989) A comprehensive mass flux scheme for cumulus parameterization in large-scale models. Mon Weather Rev 117:1779-1800

Tiedtke M, Geleyn JF, Hollingsworth A, Louis JF (1979) ECMWF model parameterization of sub-grid scale processes. ECMWF Tech Rep 10:1-53

Tomas RA, Webster PJ (1997) The role of inertial instability in determining the location and strength of near-equatorial convection. Q J R Meteor Soc 123:1445-1482

Waliser DE, Somerville RCJ (1994) Preferred latitudes of the intertropical convergence zone. J Atmos Sci 51:1619-1639

Wu GX, Liu H, Zhao YC, Li WP (1996) A nine-layer atmospheric general circulation model and its performance. Adv Atmos Sci 13:1-18

Zhang CD (2001) Double ITCZs. J Geophys Res-Atmos 106:1178511792

Zhang GJ, McFarlane NA (1995) Sensitivity of climate simulations to the parameterization of cumulus convection in the Canadian Climate Center general circulation model. Atmos Ocean 33:407446 